Portland State University

PDXScholar

Dissertations and Theses

Dissertations and Theses

Spring 6-16-2015

\title{
Therapy and the Nontraditional Transgender Narrative
}

Dylan Ellingson Waller

Portland State University

Follow this and additional works at: https://pdxscholar.library.pdx.edu/open_access_etds

Part of the Gender and Sexuality Commons

Let us know how access to this document benefits you.

\section{Recommended Citation}

Waller, Dylan Ellingson, "Therapy and the Nontraditional Transgender Narrative" (2015). Dissertations and Theses. Paper 2336.

https://doi.org/10.15760/etd.2333

This Thesis is brought to you for free and open access. It has been accepted for inclusion in Dissertations and Theses by an authorized administrator of PDXScholar. Please contact us if we can make this document more accessible: pdxscholar@pdx.edu. 
Therapy and the Nontraditional Transgender Narrative

by

Dylan Ellingson Waller

A thesis submitted in partial fulfillment of the requirements for the degree of

\author{
Master of Science \\ in \\ Sociology
}

\title{
Thesis Committee:
}

Melissa Thompson, Chair

Maura Kelly

Matthew Carlson

\section{Portland State University}

2015 


\begin{abstract}
The history of transgender identity is inextricable from the mental health industry. Since the late 1970's transgender people have required permission from mental health professionals to make medical modifications to their sex characteristics. During the time of this research, it was difficult for transgender individuals to receive the hormones or surgeries they desire without first being diagnosed with Gender Identity Disorder (GID).

This study applies labeling theory to the label of GID. Labeling theory poses that if an individual is labeled with a mental illness, they will either reject or accept the label. Acceptance of the mentally ill label will cause the individual to adopt characteristics expected of the label.

The intent of this study is to examine the relationship between mental health therapy and the formation of transgender identities. Utilizing labeling theory, it analyzes whether or not transgender participants of this study accepted or rejected the mental illness label of GID. It was originally posed that if transgender individuals accepted the label of GID, they would experience a shift in their gender identity.

However, the overwhelming majority of the twelve participants interviewed rejected the label of GID. Even though most participants rejected the GID label, many still saw a shift in gender identity while attending therapy. This thesis proposes that there may be a link between a transgender person's reason for entering therapy and identity shift. Those who felt obligated to go to therapy for the sole reason of gaining permission to change their sex characteristics saw no change in identity. However, those who
\end{abstract}


wanted help in exploring their gender with a therapist saw identity changes while in therapy. 
Abstract.............................................................

List of Tables........................................................

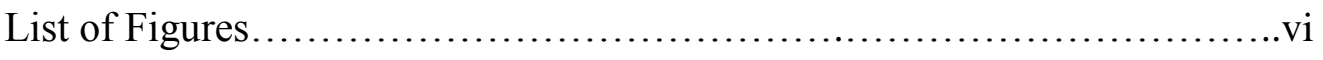

I. Introduction........................................................

II. Literature Review.................................................

Models of Transgender Care............................................. 7

Gender and Identity as Social Construction..........................10

Transgender Knowledge of Medical Models...........................12

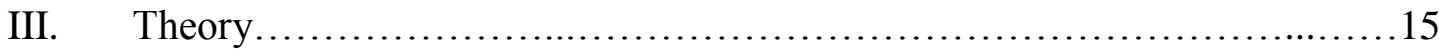

Labeling Theory................................................. 15

Self Labeling..................................................... 18

Alternate Views..................................................22

Controversy..................................................... 24

Contributions to Labeling Theory...............................26

IV. Methodology...................................................29

Sampling.........................................................

Data Collection...................................................... 33

Data Analysis................................................... 36

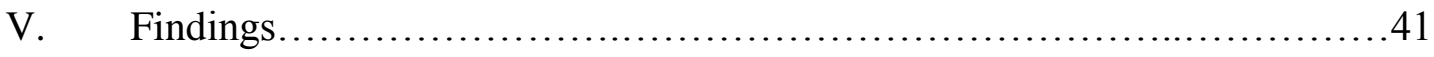

Identity Shifts.................................................. 41

Knowledge of Medical Models.....................................47

Acceptance/Rejection of Mental Illness Label.........................48

Methods of Avoidance.............................................52

Acceptance/Rejection and Social Support.............................59

Potential Reasons for Identity Shift..............................6 63

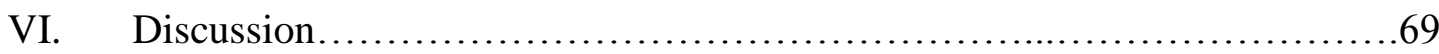

The Initial Labeling Process.....................................71

Acceptance or Rejection....................................... 74 
Desires for Changes in Medical Care.................................79

Suggestions for Future Research..................................85

Conclusion.....................................................88

References.....................................................90

Appendices........................................................93

Appendix A: Request for Stories..................................93

Appendix B: Interview Guide.....................................95 


\section{List of Tables}

Table I. Description of Research......................................68 


\section{List of Figures}

Figure I. The Labeling Process......................................28

Figure II. Dan's Gender Identity Timeline ..........................40 


\section{Chapter I}

\section{INTRODUCTION}

The transgender and medical communities share a strong historical link that persists to this day. Traditionally, it has been mental health providers who dictate what medical modifications individuals are permitted to make to their physical sex characteristics. The availability for transgender people to receive hormones or surgeries has been strictly controlled by the mental health system since the late 1970's. (Brown and Roundley 1996:100).

From the late 1970's well into the 2000's, if an individual wanted to attain hormones of surgery they first had to attain written consent from a mental health professional. The letter of consent officially diagnosed the individual with Gender Identity Disorder (GID). The guidelines for being diagnosed with GID, as described by the DSM IV, include "A strong and persistent cross-gender identification (not merely a desire for any perceived cultural advantages of being the other sex.)” (2012)

However, the notion of a "cross-gender," or that someone must identify as "the other sex" in order to be diagnosed with GID relies on the cultural construction that there are only two genders, and that the characteristics of those genders are definable. As members of society who are generally not transgender themselves, mental health professionals' constructions of gender as a binary system are thought of as truths rather than culturally relevant. (Billings and Urban, 1982). The often unexamined idea that an individual will either identify wholly as male or as female is reflected in the traditional 
transgender narrative the typical mental health provider expects to hear. As the wording in the DSM suggests, a person may have been born and raised as one sex (male or female,) but will fully identify as the opposite sex.

However, the traditional transgender narrative is not the only story told by individuals who desire to physically modify their sex characteristics. Many queer and transgender individuals identify outside of the gender binary of male or female (Roen, 2002), and some of those individuals desire to modify their bodies. This study focuses on transgender individuals who currently identify, or who identified at one point, as existing between, or outside of, the gender binary of male and female.

This study addresses the following research question:

What is the relationship between individuals participating in gender therapy and the formation of gender identity among gender variant individuals?

Gender variant individuals are defined as those who self-identify as not feeling fully male or female, but rather identify themselves as existing in between male and female, or as neither male nor female. Research examining gender variant individuals in a therapy setting has been non-existent until this time, making this study an important gateway into knowledge about these experiences. The research question focuses on the relationship between gender variant individuals and gender therapy. Gender therapy is categorized here as sessions with a mental health professional in which transgender identity is discussed. 
This study looks specifically at the idea that gender therapy may have an effect on the gender identities of gender variant individuals. In order to investigate this idea Thomas Scheff's contributions to labeling theory in mental illness were utilized. Key elements of labeling theory that pertain to identity shift were applied from the onset of this study, thus shaping the questions asked of participants, as well as the research question itself.

The elements of labeling theory applied to this study contain a process of labeling that leads to identity shift. These elements have been broken down into three parts: (1) The Initial Labeling Process, (2) Acceptance or Rejection of the Label and (3) Identity Shift. Scheff's labeling theory hypothesizes that a label itself can affect an individual's identity. In other words, if an individual is labeled, they will then internalize that label and conform to what that label implies.

Labeling theory as applied to this study looks at the label of Gender Identity Disorder (GID). As the research question states, this study aims to investigate whether there is a relationship between the formation of gender identity in gender variant individuals and gender therapy. Scheff's labeling theory has been applied in order to evaluate the potential that an internalization of the GID label while in gender therapy may be causing identity shifts in gender variant individuals. If labeling theory applies to this situation those who accept a label of GID will show a shift in identity during therapy, while those who reject the label will not.

It is hoped that this study will provide new insights into labeling theory due to its use in a subject matter it has yet to be applied to. In addition to labeling theory, this study recognizes that as the subject of gender variant individuals in gender therapy is new, this 
study may act as a modest foundation for future research into the area. Literature on this topic is sparse, and I believe a generation of new material would be not only interesting from a theoretical perspective, but also beneficial to the transgender community.

Chapter two aims to provide a base of knowledge to this study through reviewing relevant literature about (1) models of transgender care, (2) gender and identity as a social construction and (3) transgender knowledge of medical models. First models of transgender care are reviewed. Next, the historical significance of the relationship between transgender people and mental health providers is explained. The criteria for allowing access to sex altering hormones and surgeries as presented in the DSM IV is reviewed, along with opposing views to the American Psychological Association's practices. It then looks at gender and identity as a social construction, providing examples of gender variant identity that exist outside of the gender binary of male or female. Last, sociological work about transgender individual's knowledge of transgender medical models is reviewed. The review of this type of work exposes a need for further research on the topic.

Chapter three continues where the literature review leaves off, providing more insight into the theoretical framework of this study. As explained previously, this study is based on elements of labeling theory. Chapter three explains both Thomas Scheff and Peggy Thoit's contributions to labeling theory in mental health. It also explains how the specific topics of this study, gender variant identity, and mental health providers, relate to labeling theory. It then goes on to discuss alternative views to, as well as controversy surrounding, labeling theory. The chapter ends by explaining what this study can 
contribute to labeling theory. This is done through outlining the specific elements of labeling theory that will be analyzed.

Chapter four explains the methodology utilized in this study. The demographics of the sample are outlined here, as well as the sampling method. Methods of data collection, as well as the reasons these methods were utilized, are also explained.

Chapter five presents the findings of the research. First, it outlines the level of identity shift that was seen in participants, as well as what form those shifts in identity took. It then discusses participant's knowledge of medical models. Whether an individual accepted or rejected the label of Gender Identity Disorder is presented in detail, followed by discussion of factors that may have contributed to either rejection or acceptance.

Chapter five also discusses how this research model would fit into current day practices. This research took place in 2011 on the cusp of an change in the mental health system's official stance on the relationship between transgender individual's access to changes to their physical sex characteristics. In 2011, the World Professional Association of Transgender Care (WPATH) published changes to their Standards of Care (SOC) which were adopted by the American Psychological Association (APA) in 2013. Data for this study was collected and analyzed in 2010 and 2011, during which the APA Diagnostic and Statistical Manual IV (DSM IV) and WPATH SOC 6 were the official stance.

Chapter six begins reviews the findings in terms of their theoretical frame. The application of the research to labeling theory is discussed, as well as areas the study reveals that may contribute to the body of knowledge of the labeling process. It is here that the changes to the relatively recent SOC and DSM are examined. Taking these 
changes into account, suggestions for future research in the area of both labeling theory and transgender mental health care are presented. The chapter also discusses transgender desires for change within the mental health system as stated by participants. 


\section{Chapter II}

\section{LITERATURE REVIEW}

\section{Models of Transgender Care}

The transgender community has a history linked to the mental health community. Prior to the late 1970's all degrees of transgender presentations were viewed as neurosis. Gender variance was treated under the assumption that curing the patient involved removing gendered tendencies that did not correspond to the patient's sex (Gainor 2000:150). In the late 1970's Dr. Harry Benjamin introduced the Standards of Care (SOC,) (Brown and Roundley 1996:100), a set of guidelines for the treatment of trangender individuals.

The SOC has been consistently updated to comply with current attitudes toward transgender treatment in the mental health community. From Harry Benjamin's first iteration of the SOC and onward, the American Psychological Association (APA) has adopted the SOC suggestions into the Diagnostic and Statistical Manual, (DSM.) This is significant because it is the DSM, not the SOC, which is the standard of treatment by mental health professionals nationally. During the time data was collected for this study, the Standards of Care were on their sixth iteration (SOC 6.)

The SOC 6 facilitated treatment based on the diagnosis of Gender Identity Disorder (GID) as a mental illness whose prescription for treatment is physical and social transition from one sex to another. The SOC 6 enforced the idea of a gender binary through posing strict criteria for what it means to be male or female. Under the SOC 6, in order to be diagnosed with GID one must meet guidelines that prove that their mental 
state is that of the sex other than which they were assigned at birth. While the SOC opened the option of physical transition to the transgender community, it limited these medically assisted body modifications to those diagnosed with GID by a therapist.

Under the SOC 6, in order to be prescribed hormones or surgeries a person must place themselves in a treatment situation that operates under the assumption that there are only two genders (Denny 2004:28). While transgender individuals seeking gender therapy do so for a variety of reasons, one common reason is to potentially gain a prescription for medically assisted body modifications of sex characteristics. This prescription often comes in the form of what is referred to as a "letter." A letter is a written statement from a mental health professional signaling their approval that doctors provide sex altering medical services to the individual in question.

What was originally Harry Benjamin's organization, created to advocate a model for transgender care, has been renamed The World Professional Association for Transgender Health (WPATH). Like Harry Benjamin, WPATH modifies and publishes new editions of the SOC, which have undergone multiple revisions over the last several years (Lev 2009). As of the SOC 6, it still remained that the SOC support GID as a diagnosis for transgender individuals. The Diagnostic and Statistical Manual of Mental Disorders (DSM IV,) compiled by the American Psychological Association, is heavily influential in the actions of mental health professionals. It acts as a guide to diagnosis of what are deemed mental health problems, including gendered behaviors. Horwitz explains that "The disease categories of the DSM are not just one particular way of viewing mental illness among other possibilities; instead they are lenses that reflect the assumed objective reality of these conditions" (2003:5). The DSM not only directs 
mental health professionals to interpret behavior, it also allows little room for variation in diagnosis.

The DSM IV's section concerning gender identity is heavily guided by the WPATH SOC, leading to the majority of the mental health community supporting the idea of GID. However, it should be kept in mind that some consider mental illnesses social constructions, created through value judgments on the part of the mental health community. Many of the value judgments present in the DSM IV are heavily influenced by gender stereotypes. The GID diagnosis pathologizes individuals who act outside gender norms without critically analyzing how societal intolerance (present within mental health professionals as well as most members of society,) plays a role in that assessment (Prior 1999). Many transgender advocates feel justified in speaking against clinical diagnosis of transgender behaviors on the basis that the normalization of specific gender presentations through the pathologization of others is unjustified (Vance et al. 2009:3, Corneil et al. 2010).

Possibly inspired by this advocacy, the gender identity disorder model in the SOC is being adopted by therapists, the Transgender Model. This model was created in order to make it easier for gender variant individuals to express a broader array of gendered presentations to their therapists while maintaining the possibility of procuring a letter. (Bolin as cited in Denny 2004). According to Anne Bolin, this model is gaining popularity as therapists are beginning to educate themselves about gender variance. (Denny 2004:33)

A step beyond the Transgender Model is the model of informed consent. While transgender identity is pathologized by much of the mental health community, that 
discourse does not resonate with all individuals. Many within the transgender community, as well as their allies, suggest that it should not be required to see a mental health professional prior to receiving help toward medical transition. Requiring those who seek to change sex characteristics to achieve permission from a therapist while not requiring the same of others who seek permanent surgical body modifications robs transpeople of their autonomy (Hale 2007). Under informed consent an adult individual who seeks physical modifications to their body will be granted access to surgeries and hormones they seek. Informed consent states that a client should be presented with information about the possible effects of the surgeries and hormones on the body, and then given the freedom to make the personal decision as to whether or not the benefits outweigh the drawbacks. Informed consent focuses on whether or not a patient understands what will happen to them should they move forward with transition, rather than whether or not that person should be allowed to transition (Lev 2009).

\section{Gender and Identity as Social Construction}

This study looks at a particular subgroup within the transgender community, those who identify as existing between, or outside of, the gender binary. The term "gender variant individual" will be used for this study due to the lack of universal definitions within the transgender community. Two individuals who use a similar label to describe themselves may identify in very different ways. However, the term "genderqueer" tends to be understood as a label denoting gender variance. (Nestle, Wilchins and Howell 2002). Those who identify themselves as genderqueer believe that they exist in a state that does not conform to society's definition of what it is to be a "man" or "woman." 
Roen (2002:505) describes the concept of gender variant identity (as it is presented in this study) as "both/neither." While many transpeople identify as wholly male or female, "both/neither refers to a transgender position of refusing to fit within categories of man or woman." Often, but not always, the gender variant identity is connected to a political awareness. Roen writes that

Transgenderism is a political movement seeking to challenge the belief that every person can be categorized simply as one of two sexes. One political strategy instituted by transgenderists has been to promote transsexual visibility and, in particular, to encourage transsexuals to be out as both and neither. This both/neither stance has come to be privileged over passing as women and men.

Gange and Tewksbury (1999:77) also describe a gender variant identity as political, stating that “ $\ldots$ our informal observations of the transgender community suggest that a vocal minority within the nationwide (trans)gender movement advocate rejecting binary systems of sex, gender, and sexuality."

While it is true that the gender variant identity is often political, it is not fair to say that this is always the case. The transgender population is underrepresented, with subgroups of that population being represented even less. While most of what is written about gender variance comes from a political stance, there are gender variant individuals who do not adopt a political identity. For some, being gender variant comes from a knowledge (to varying degrees) that gender is a social construction.

West and Zimmerman (1987) describe the concept of gender as a social construction. They explain that gender is not something innate, but instead something that exists due to a continual performance of what it means to be a man, or what it means to be a woman. Billings and Urban (1982) explain that just as the idea of male and female are constructed through social interaction, transsexualism is constructed similarly. We 
understand what it means to be transsexual due to cultural meaning. Gender variant

people do not conform to the idea of being male, female, or transsexual. This may create obstacles for them should they choose to medically transition, as the Standards of Care state that being permitted to change one's sex characteristics requires a strong identification with a particular gender.

\section{Transgender Knowledge of Medical Models}

The mental health community is not the exclusive holder of medical models that diagnose transgender behavior. Many transpeople belong to both formal and informal support networks, both online and through personal interaction. Information about the requirements that must be met in order to gain permission to transition is readily available to most who seek it. Billings and Urban write about the relationship between transpeople and providers of medical body modifications in its early days.

The psychiatrist's task was to judge how well patients' self-reported life histories fit the criteria for transsexualism established in the medical literature. Since the reputable clinics treated only "textbook" cases of transexualism, patients desiring surgery, for whatever personal reasons, had no other recourse but to meet this evaluation standard. The construction of an appropriate biography became necessary. Physicians reinforced this demand by rewarding compliance with surgery and punishing honesty with an unfavorable evaluation. The result was a social process we call "the con" (1982: 273).

With the emergence of the Harry Benjamin Standards of Care, the concept of transsexualism allowed individuals to seek gender reassignment through surgeries and hormones. However, these body modifications were not available to all, as the strict criteria set by the SOC separated who was deemed worthy of such services from who was not. Through attaining knowledge of the history that a "true transsexual" was supposed to 
possess, transpeople could then mimic these histories in order to be approved for sex reassignment.

This necessity for misrepresentation is not relegated to the past. Speaking of the $21^{\text {st }}$ century, Dallas Denny writes that "The preoperative individual recognizes the importance of fulfilling caretaker expectations in order to receive a favorable recommendation for surgery, and this may be the single most important factor responsible for the prevalent mental-health medical conceptions of transexualism" (2004:29). Denny's analysis makes clear an issue that arises from the transgender community's perceived need to lie to mental health providers. If transpeople are not accurately describing their gender histories to their mental health providers, the mental health community may come to understand the transgender community as homogenous. In other words, more gender variance exists than the profession of therapy is aware of. This is a result of the knowledge that gender variant individuals hold that in order to be allowed to do what they wish with their body, they must perform the role of gender identity disorder correctly.

Transgender interaction with medical models is not always cut and dry. While in many cases transpeople may feel they have to present in a certain way in order to gain access to services, in other cases transpeople may be adapting to a society which does not understand their unique needs. Dewey (2008) presents a more nuanced view of the relationship between transpeople and medicine. She supports the notion that transpeople selectively disclose their histories in order to receive the services that they want. However, Dewey goes beyond the explanation that transpeople mirror model transsexual behavior only for the purpose of achieving surgery and hormones. 
In many cases, medical professionals lack knowledge about transpeople. Dewey (2008:1351) writes that "Trans-patients supporting existing medical knowledge by adopting particular language accepted in the field. Even if patients find the doctors' information about people like them to be limited, they continue to support the medical structure by attempting to work within it." Due to the doctor's lack of knowledge about trans-identity, the transperson finds themselves in a position in which communication about gender identity is limited. Traspeople then adapt by adopting the medical profession's language about gender identity in order to best relay their situation. Dewey explains that this adoption of the medical community's language reinforces the medical community's ideas of transgender people through failing to describe the intricacies of individual people's gender identity. 


\section{Chapter III}

\section{THEORY}

This chapter outlines the contributions of Thomas Scheff and Peggy Thoits to labeling theory. It also highlights alternate views and controversy surrounding the theory. Last, the application of labeling theory to the research question is presented. It is proposed that labeling theory will aid in the research and analysis of gender variant individual's identity in the setting of gender therapy.

\section{Labeling Theory}

This research is influenced by labeling theory, and has been particularly influenced by Thomas J. Scheff's description of the "framework" of labeling theory. Scheff explains that what are commonly referred to as "mental disorders," or mental illnesses, are usually thought of as an issue on the individual level, but are really an individual's reaction to society. He goes on to explain that mental illness is in many cases not actually an illness, (which is the result of physical malfunctions of the body,) but rather deviant behavior or social norm violations, which he names "residual deviance" (1963:438). Transgender individuals can be said to be breaking gender norms, as they often do not conform to the social roles assigned to their biological sex. While many feel that this behavior is a mental illness, it can be argued that a label of mental illness for transgender people is the result of non-normative gender behaviors being labeled as deviant by society.

Scheff (1963) explains that while deviant acts are committed often, they are not always labeled. In many cases, socially deviant acts are accepted, explained away or 
denied by individuals within the community. In other cases, the act is rejected by society and thus labeled as deviant. It is not the deviant act which varies, but rather the community or society in which the individual lives.

This applies to gender deviance as well. If an individual engages in an act which transgresses gender, this act will have little to no effect on them without the reaction of society. If society denies that the gender transgression is deviant, then the individual can continue on in their life without being labeled mentally ill. However, if society rejects the gender transgression, that individual will be labeled as deviant, and potentially mentally ill (1984 65). Within the United States there are few places, if any, which do not rigidly police gender norms. The expectation that certain roles apply to a particular sex is widely believed, and is not escaped by the mental health professional community. In fact, the psychiatric community legitimizes the labeling of transgender individuals as mentally ill through maintaining gender transgressions as a diagnosable disorder.

The notion of transexualism, or a person "being" transgender, has been highly medicalized. As discussed in the previous chapter, transpeople seeking modifications to their sex characteristics are labeled by the mental health system as having Gender Identity Disorder (GID). Scheff writes that "The stabilization and uniformization of residual deviance are completed when the deviant accepts the role of the insane as the framework within which he organizes his own behavior" (447). While Scheff does not specifically address the GID label, his work can be applied to this issue. In the case of gender, I argue that the mental illness "framework" of transexualism is the idea that gender and sex should always exist in harmony. Accepting the role of mentally ill is identifying as having GID. 
Scheff's framework describes the situation for those labeled mentally ill as relatively powerless. He explains that labeled deviants are controlled by social factors through positive reinforcement when they accept the label, and sanctioned if they attempt to leave the role. He writes that "...patients who manage to find evidence of 'their illness' from their past and present behavior, confirming the medical and societal diagnosis, receive benefits" (1963 449). This is particularly clear for transgender individuals. Gender transgressions are not supported within our society, and many individuals face hardships due to the fact that they are rejected by society because of their presentations. (Grant et al. 2010, Davis \& Wertz, 2010). The opportunity to explain their differences as a medical "problem" can alleviate some stress, as they now have a justification about their behavior to present to the world. Furthermore, those who prove that they have had Gender Identity Disorder throughout their lifetime, through providing examples of past and present behavior, are rewarded with the ability to transition physically.

A physical transition (for those who end up being perceived fully as the sex of which they identify) can alleviate much of the daily rejection from society previously experienced by the individual. Alternatively, those who choose not to transition, but instead to live in a state of physically non-normative gender presentation, can be said to be in a state of exponential deviance. The original act of being transgender is in itself deviant, which is then multiplied by the deviance associated with rejecting society's prescribed idea that transgender individuals should alter their bodies in order to physically conform to societal norms. 


\section{Self Labeling}

It is also possible that some who take on the label of transsexual do so on their own accord. Peggy Thoits describes the concept of self labeling. Unlike the majority of labeling theory, the theory of self labeling describes situations in which the individual voluntarily takes on a deviant label and seeks treatment for it (1985 222). Thoits describes three major assumptions of the self labeling process (1985 223). By using Thoits' three assumptions to look at transgender identity and the labeling process it becomes clear that in some cases individuals are not exclusively affected by the labeling of the medical community, but instead, or in addition to this, may in many cases be affected by self labeling.

The first of the three assumptions in self labeling is that an individual must possess knowledge as to what actions society views as normative in order to be able to recognize their own behavior as deviant. Men and women are expected to perform different, sometimes oppositional, roles in our society. As Terrance Real explains, "Girls are pushed inward, boys are pushed outward. Some of this directionality may be inherently biological, but most agree that the process is a direct web on nature and nurture" (290). Social norms regarding gender are widely understood in our society. As transgender people were socialized in our society, it can be inferred that the majority of transgender individuals understand what is expected of their biological sex and thus understand when they violate such norms.

The second assumption of self labeling is that norm violations must have the potential to be grouped into culturally understood categories. In other words, in order to be able to self label, the society in which one participates must have a name for the 
deviant act being committed. The label of GID has previously been discussed in great detail. GID is a medicalized label that was originally provided by mental health professionals, but which now exists both in the medical industry and possibly in the queer community. It is unclear to what extent the GID label of deviance for those who present outside of gender norms is readily available, is assessed through the interview guide. If the label of GID is learned by participants through their communities, it will show that in some cases within the queer culture there exists a label of deviance for those who present outside of gender norms, thus supporting Thoits' second assumption.

Alternatively, some transgender individuals choose to adopt labels that are not recognized by the society as a whole, yet are readily accepted by most queer people. This concept does not seem to fit with Thoits' second assumption, but can be supported by claims she later makes about the connectivity between the ability to resist negative self labels and a strong sense of community. This idea will be addressed more thoroughly later in this section.

The last of the self labeling assumptions that Thoits describes is that in order to self label, an individual must have motivation to conform to the norms of the culture in which they reside. It is over simplistic and inaccurate to state that all those who identify with the transsexual label feel a desire to conform to society's gendered expectations. Regardless of intent, taking steps to be perceived as the sex to which one's gender most closely matches is moving towards a place of greater social acceptance. Assuming that a transitioned individual most often perceived as the gender to which they hope to be perceived, that individual is less often seen as breaking gender norms, and is thus seen as conforming to norms. 
Because there are a variety of multidimensional reasons why an individual chooses to transition, it cannot be said that all transsexuals do so in order to conform to societal norms. However, Thoits' third assumption of self labeling may be relevant in regard to all transpeople. Research into the motivation of transsexual identity and transition is needed in order to determine whether or not Thoits' third assumption can be applied to some instances of transsexual identity. For the purposes of this initial investigation, it will be said that some of those who identify as transsexual may feel motivated to conform to social expectations, and thus can be considered to comply with Thoits' third assumption.

Social support may also have an effect on whether or not an individual self labels. Thoits explains that the process of self labeling may be dependent on ones level of social support. The ability to avoid or accept a label rests on an individual's level of connection to their peers, as well as what communities they exist in. For the purposes of this study, the label that an individual would choose to adopt or reject is that of GID. Thoits explains that support from similarly structurally strained individuals can lead to a rejection of a deviant label. When one sees others behaving in ways that are similar to themselves, they may feel less deviant in their actions. Peers can help in restructuring how an individual's thoughts and behaviors are conceptualized in order to make them feel acceptable, even if they are acknowledged as existing outside the norm (238).

An example of social support for transgender individuals is the genderqueer community, which is comprised of people who fit the definition of gender variant described earlier. The genderqueer community's assertion that gender is a social construction and that living a life incongruent with gender norms is preferable, functions 
to legitimate gender variant identities. Following Thoits' theory, the genderqueer community may act as positive social support, enabling transgender individuals to reconceptualize gender variance as a positive trait, thus avoiding the adoption of a GID label. Alternatively, those without an active support network may find it more difficult to claim a gender variant identity.

That being said, Thoits makes it clear that social support does not always cause an individual to avoid labeling. She writes that "individuals often solicit advice from others about emotional problems in order to confirm their own tentative self-labeling and treatment-seeking decisions" (239). In this situation an individual may have the desire to reject identifying as having GID, yet feel a lack of support for this rejection. If those within the transgender community support the label of GID, it is less likely for an individual within that community to reject the label. Social support from others who identify as having GID may help an individual who self labels as having GID find the strength to assert this identity.

One of the goals of this research is to allow for a comparison of identity outcomes of individuals who exist under the umbrella of transgender. While this is not a longitudinal study, I will collect data of the individual's self reported memories of identity both before and after gender therapy. While the primary purpose of this research focuses on the interaction of the gender variant individual and gender therapy, Thoits' work makes it clear that social support needs to be taken into account. I feel that failing to ask about an individual's level of social support would create a less complete picture of the relationship between therapy and labels of gender identity. 


\section{Alternate Views}

“Models, Muddles and Mental Illness Labeling” by Allan Horwitz (1979)

critiques labeling theory through focusing on arguments posed by Thomas Scheff.

Horwitz himself is a labeling theorist, yet takes issue with the divide he sees between labeling theorists and those who support a psychiatric model. Horwitz's most developed and convincing argument is summed up when he writes "...to demonstrate that psychiatrists are often mistaken in their decisions, Scheff must adapt to the concept of mental illness that he initially attempted to replace" (1979 298). Horwitz argues that while those who support labeling theory present themselves as separate from those who support the psychiatric model, the former group is actually dependant on the latter. Labeling theorists, according to Horwitz, focus on mental illnesses as rule breaking behaviors. He says that labeling theorists believe that mental health professionals use the term "mental illness" to explain deviance that is not easily categorized by our culture.

He goes on to explain that labeling theorists believe that mental health professionals support the psychiatric concept. The psychiatric concept is explained as the process of grouping symptoms, explaining the cause of symptoms, and then attempting to control the symptoms. Mental health professionals who support the psychiatric model of GID believe that there are a list of behaviors inappropriate to each of two sexes. If an individual displays inappropriate behaviors they can be classified as mentally ill and in need of treatment.

Horwitz's argument fails to address the limitation of language within our culture. Horwitz accurately states that in order to discuss what society deems mental illness, labeling theorists, including Scheff, often acknowledge certain traits as "authentic" 
mental illnesses. Horwitz criticizes Scheff's pronouncement that the majority of what are labeled mental illnesses are not legitimate. The argument is that if one claims that most mental illnesses are not legitimate, some mental illnesses then must be considered to be legitimate. If a case can be made that mental illnesses exist, then the strength of the labeling theory argument is weakened.

With that being said, while Horwitz criticizes labeling theory, it seems that he criticizes those who practice it more than the theory itself. It seems that what Horwitz objects to is the polarization of those who support labeling theory and those who support the psychiatric model. According to Horwitz, labeling theory's purpose is not to "challenge" a psychiatric model, but instead to argue that it is often applied to situations that it shouldn't be applied to (298). To say that mental illness does not exist is not a claim that Scheff makes. Rather, many of the behaviors that are regularly attributed to mental illness are not illnesses, but acts that clash with societal norms.

As stated earlier, it can be said that available language, which Horwitz does not address, is responsible for Scheff's dependence on the psychiatric model. Labeling theorists acknowledge that what are labeled as mental illnesses are labeled as such due to societal forces. However, these theorists also exist within this society, and are constrained by societal definitions. When acknowledging "true" mental illness, a labeling theorist may simply be attempting to make their work accessible to the public.

What should be recognized is that while the "symptoms" of what are labeled mental illness may exist, the idea that these symptoms are negative is what labeling theorists need to address. If what we call symptoms were accepted or ignored by society, then the individuals who displayed them would not be thought of as mentally ill. Horwitz 
seems to feel defensive about Scheff's criticism of the psychiatric model without addressing why that model may be under attack.

\section{Controversy}

It should be noted that the combination of labeling theory and the research question may be perceived as controversial or offensive. Many in both the psychological and transgender community believe strongly that being a transsexual is a condition whose appropriate treatment is medical transition, and that the existence of the diagnosis of Gender Identity Disorder helps provide valuable services to those who desire physical transition. (Vance et al. 2009, Corneil et al. 2010). Also controversial are the writings of Thomas Szasz. Szasz believes that most of what are labeled by the psychological community as "mental illnesses" are not illnesses at all, and instead opts to describe them as "problems of living" (1974:113).

It is explained by Szasz that calling a person's problems of living a "mental illness" is inappropriate because the word "illness" implies that something physical is wrong with the body. While the mental health community claims that mental illnesses exist due to malfunction within the body, Szasz says that this has not been proven to be fact. Even more important is Szasz's assertion that labeling a group of "symptoms" as mentally ill is a value judgment 1974 (114). He writes that “...it does make a difference... what the psychiatrist's socioethical orientations happen to be; for these will influence what is wrong with the patient, what deserves comment or interpretation, in what possible directions change might be desirable, and so forth" (1974:116).

Gender Identity Disorder is listed in the DSM, and is seen by many to be a mental illness capable of being treated. Using Szasz's point of view, we can question whether or 
not people who desire to display behaviors or sex characteristics contrary to their assigned sex are ill. Like the above quote explains, those in the psychological community are not immune to cultural biases. Their attitudes reflect those of the society we live in, which believes that it is natural for men and women to look and behave in ways that are particular to their sex. When a member of society deviates from this expected behavior they are viewed as abnormal. However, this does not mean the deviant individual is mentally ill, but only that they are behaving in ways that contrast with societal expectations.

Szasz says the reason society views someone as having a mental illness is because that person's way of existence creates disturbance in the way others relate to them. He writes, "It is implicit in this view that social intercourse between people is regarded as something inherently harmonious, its disturbance being due solely to the presence of "mental illness"' (114). American society is not equipped to accept variations in gender identity. The disharmony that gender variations create is demonstrated by the overwhelming amount of hate crimes transgender and transsexual individuals are subject to each year. However, while varying gendered presentations do create disharmony, this does not mean that transexuality should be seen as a mental illness. Gender variance is not an illness, but instead is a deviant act that is labeled an illness by those who have the power to do so.

Szasz specifically cites power as a determinant in what is labeled mentally ill and what is not. He states that the power to define norms also allows for the power to define deviance (115). The mental health professional community holds much of this power. 
Through defining certain gendered presentations as outside the norm and thus deviant, they are creating a system which marks particular individuals as others.

Szasz cautions the psychological community to examine the ethics in exercising this power. Similarly, transgender advocacy groups have been speaking out about the classification of transexuality (gender identity disorder) as a mental illness. Many feel that gender identity disorder should be removed from the DSM completely (Vance et al. 2009:3, Corneil et al. 2010).

\section{Contributions to Labeling Theory}

Scheff (1984) suggests that “...studies of the conditions under which normalization and labeling of residual rule breaking occur" (97). Through applying the theory into a subject matter it has yet to be applied to this research will add to labeling theory's theoretical applicability. It may also facilitate identifying parts of the theory that need to be further assessed. The primary research question for this research is:

What is the relationship between individuals participating in gender therapy and the formation of gender identity among gender variant individuals?

This question is being addressed through the utilization of labeling theory.

The research looks closely at gender variant identity and its relation to therapy by applying it to concepts found within labeling theory. Scheff explains that labeling theory involves an individual receiving a role, (in this case the role of having GID,) and then playing out that role (1984:70). As this study is looking at the relationship between individuals participating in gender therapy and the formation of gender identity, its focus 
is on labeling that occurs within the setting of therapy. For the purposes of this study, the labeling addressed is between the therapist and client. The research examines how well the labeling theory model applies to gender variant individuals attending gender therapy.

As figure one illustrates, the labeling process being examined can be broken into three parts. The first portion of the labeling process is that of the presentation of the label. If the labeling occurs within the therapy setting, it is expected to come in the form of GID from the mental health professional. The second section of the labeling process is a reaction to the label in the form of acceptance or rejection. Labeling theory assumes an acceptance of the mentally ill label due to the difficulty of rejecting a label if the norms broken are not ignored by society (1984 63). If the label is accepted Scheff explains that the individual then further adopts characteristics associated with that mentally ill label (1984). It can then be hypothesized that those who accept a label of GID will show a shift in identity presentation during therapy, while those who reject the label will not. The third and last part of the labeling process includes measuring a shift in gender identity as it compares to acceptance or rejection of the GID label. Measuring a shift in identity can be done by analyzing shifts in how a participant described their identity before and during gender therapy. Analysis of the three processes presented in figure 1 allow for a thorough application of the research question to labeling theory. If any of the processes of labeling theory apply to gender variant individuals in the setting of gender therapy it may contribute to the potential for the theory to be applied to more mental health labels. 
Figure I. The Labeling Process

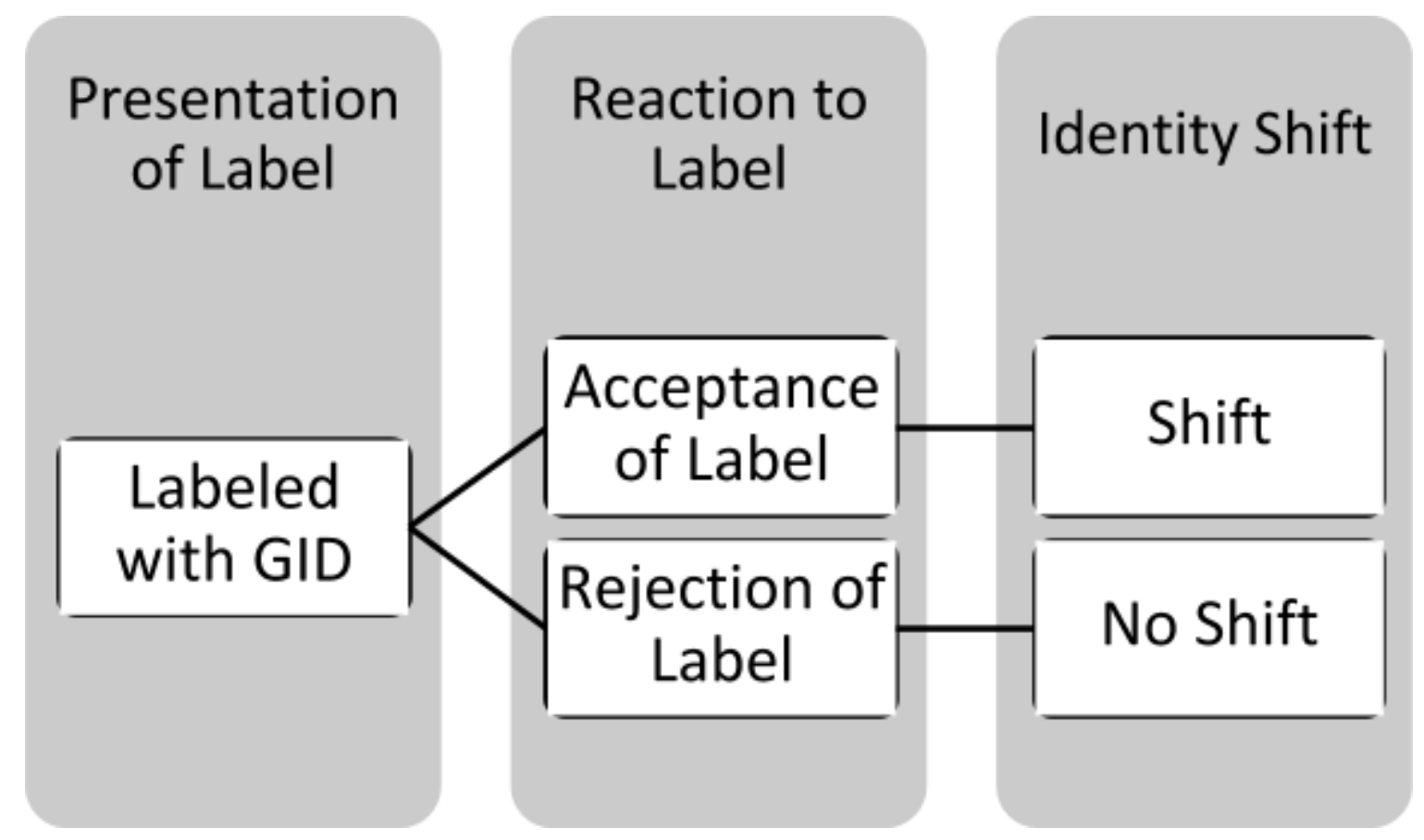




\section{Chapter IV}

\section{METHODOLOGY}

Chapter two presented a history of the transgender community and their relationship to mental health professionals, along with an understanding that very little research has been devoted to this topic. A qualitative approach to this research was chosen for a variety of reasons, many of which center around the fact that the amount of research on transgender identity is minimal and even less has been written about this area from a sociological perspective. It is for this reason that an exploratory approach to this project was the best choice. Through utilizing in depth, semi-structured interviews I was able to obtain a broad amount of detail about the identities and experiences of my participants. This large amount of detail was not only used to address the research question, but also helped provide an understanding of specific issues surrounding gender identity and therapy that should be focused on in the future.

A qualitative approach allows the transgender community to state their feelings about the medicalization of their gender identities from their perspective. Traditionally control over transpeople's bodies has been taken away from them and put in the hands of others. Qualitative research makes it possible to give voice to marginalized groups (Ragin 1994). Through interviewing transpeople I attempted to present their identities and experiences as close as possible to their own perspective. Through in-depth interviews I addressed the following question:

What is the relationship between individuals participating in gender therapy and the formation of gender identity among gender variant individuals? 


\section{Sampling}

After attaining IRB approval to interview participants for this project it became clear that the next step would be figuring out how to best access the population. The transgender community is geographically diverse and difficult to find. Like many subpopulations, when working with members of the transgender community sampling becomes an issue. Accessing the trans community is difficult due to its relatively small size. This study focuses on a subset of the transgender community, those who at one time have identified as outside of the gender binary, thus making it even more difficult to sample. Access to the trans community is also limited because of the concealed nature of gender identity. It is not possible to understand an individual's gender identity or sex without asking them to reveal their status. Many transgender individuals choose to live their lives as "stealth," in which they choose not reveal their gender history in most situations.

The relatively small population being researched combined with difficulty in locating and accessing this group made it impractical to create a sampling frame. Instead, snowball sampling through social media was utilized in order to locate potential participants for this study. The Request for Stories (See appendix A) included both an online video and pdf invitational letter. The video was uploaded to YouTube, with the accompanying invitational letter posted in the video's text box. I chose to sample using social media in order to be able to access individuals from around the United States, including those who may normally be difficult to find due to being stealth or not connected to transgender groups or organizations. 
The YouTube user Charlie (of the channel freshlycharles) provides an example of transgender utilization of online social networks. In a video posted in November of 2010, Charlie spoke about his YouTube experience. In writing about his primary reason for joining YouTube he said that, "In the beginning, for six months of my blogging it was a combination of building a trans community, basic support..." Charlie speaks of blogging on YouTube, which is also commonly referred to as "vlogging," in order to describe his process of recording videos of himself as he describes his thoughts and experiences, and then posting them online for other people to watch and comment on. Many transgender individuals post videos on YouTube regularly, while others watch and comment on videos to varying degrees. I was interested in hearing not only from people who live in large, queer friendly cities, but also people who were more isolated. Utilizing youtube allow me to access a community that does not physically live in one place, yet congregates virtually in order to make connections with one another.

After posting the Request for Stories to YouTube I then established connections with the owners of YouTube transgender community channels. A YouTube channel is a YouTube page that hosts several weekly videos from multiple regular contributors. Often contributors have a specific day that they are expected to upload their video on, thus mimicking a television channel in its predictability. When I contacted YouTube channels with a transgender theme I requested that they either a) post my video to their channel directly or b) mention my research in their own video and provide a link to my channel in the description that appears next to their video. Additionally, I posted the video to various transgender themed Tumblr communities. Tumblr is a popular social media site that 
allows very specific communities (for instance, those who identify as genderqueer or transsexual men of color) to share media and ideas with each other.

I chose to post on both YouTube and Tumblr in order to maximize the amount of people who would see the Request for Stories. Potential participants could watch the video inviting them to participate in the study, and were then prompted to click a link provided next to the video for the letter. The request for stories briefly outlined a description of myself, the project, and why I hoped the project would benefit the trans community.

It also outlined the three criteria individuals had to meet in order to participate in the study. First, they must have been involved in therapy sessions in which they specifically discussed their gender identity. Second, in order to participate in the study individuals should have self-identified as somewhere outside of the gender binary at some point during the time they were in therapy. Identities that may fit this category may include, but are not limited to, genderqueer, gender neutral and genderless. Last, during some point during the duration of their therapy sessions they must have potentially desired receiving a letter from their therapist that would allow them to receive surgery and/or hormones. The Request for Stories then asked for those who wished to participate in the study to e-mail me. Individuals who self identified as meeting the criteria for the study were accepted into the research.

\section{Sampling Shortcomings}

It should be noted here that the sample of participants in this study lacked diversity in several ways. First, the majority of participants were caucasian. Second, there were no participants who were assigned the sex of male at birth. Last, and potentially 
most importantly, the majority of the sample was highly educated. All but one of the participants had attended college. The sampling strategy of asking for those identified as "gender variant" may have played a part in attracting a highly educated sample. Concepts of gender as a social construct are often introduced in college, thus making it more likely for college educated individuals to adopt identities outside of the gender binary. This could be avoided in future research through sampling for all individuals who identify as transgender instead of only those who identify with a more niche label.

\section{Data Collection}

\section{Collection Method}

Taking into account time, this study aimed for and succeeded in collecting data from 12 participants. The research consisted of semi-structured interviews. Contacting of participants took place only after IRB approval for this project was received. Due to the location of participants, recorded interviews took place over the phone. Negotiations as to when the interviews would take place occurred through both e-mail, online chat services and the phone. I conducted interviews in both my office at Portland State University and my home. Similarly, I advised during negotiations that participants set aside a quiet space and two hours of time in order to be interviewed. Interviews were semi-structured and were kept as conversational as possible. My goal was to minimize feelings of power differences. I thanked participants for allowing me to interview them and stated that I was interested in their unique perspective. I also told them to feel free to ask me any questions about the interview process as the interview proceeded.

Interviews lasted between 45 minutes and two hours. At the conclusion of each interview I stated that I had no further questions, and invited participants to engage in 
additional dialogue if they so desired. About half of my participants took me up on this offer. Many wanted to discuss aspects of my research, such as what made me choose my topic, or what I planned to do next. Others brought up aspects of trans identity not discussed in the interview, often asking about my own identity. I responded to their questions, as I did not feel uncomfortable with what I was being asked. I felt it fair and respectful to respond to their questions, as they had answered mine.

\section{Interview Guide}

The interview guide focused on gaining information surrounding participants' identities, feelings about mental health services as they apply to the trans community, and personal experiences in therapy. Data were gathered through a series of questions, several of which were designed to invite longer narratives about identity and experiences which allowed me to first hear what the participant found most important before probing for additional data. The interview guide (appendix B) is divided into five sections (A-E,) each of which was designed to address a different aspect related to the research.

Section A was designed to measure the participant's gender identity over time. It invited the participant to "tell a story" in order to create a timeline of events starting before they questioned gender and ending at the present time. In letting the participant have the initial freedom to narrate their gender history, it was hoped that the data would show what life events participants related to shifts in identity. This section was also intended to help identify a participant's current identity, as well as past identities. This information was important to the research, as without knowing how a person currently identifies in relation to their past identities it is not possible to assess identity shift. 
Section B of the interview guide looked at societal perceptions. Societal perceptions are important to the research, as they are integral to labeling theory. As Scheff (1963) explains, society plays a large role in whether or not a person is labeled as deviant. A behavior is not deviant before it is labeled according to Scheff. If those around an individual do not respond negatively to their gendered presentations, then that person may continue on in their behavior without being labeled. Through measuring the participant's perceptions of other's reactions to their gendered presentations by their community members I hoped to assess whether these reactions may contribute to them accepting the label of Gender Identity Disorder (GID.)

Measuring societal reactions was also included in order to relate to self labeling theory. As Thoits (1985) explains, in order to self label as deviant an individual must possess a desire to conform to cultural norms. Society acts as a mirror of the self, reacting negatively to norm violations. If participants reported negative responses to their gendered presentation then it could be inferred that they are breaking norms. A follow up probe as to how an individual felt when reacted to in a negative light was expected to explain whether or not that individual may wish to conform to societal norms.

Questions in section C measure social support. Thoits suggests that social support is integral to self labeling, as well as to the rejection of labeling. According to Thoits a supportive community can do one of two things. First, a supportive community can help an individual to reject interpreting their actions as deviant, thus helping them reject the label. Alternatively, the community may provide support through urging the individual to accept the fact that they are non-normative, thus accepting the deviant label. In the absence of social support the individual is seen as likely to accept a deviant label. By 
measuring the extent of involvement the participant has in queer and transgender communities, as well as whether or not they feel those around them are supportive of their identity, Thoits' claim can be addressed.

Section D measures the relationship of the participant to the medical model of GID in two distinct ways. First, it asks to what extent the participant understands key medical terms of the medical industry, such as the Harry Benjamin Standards of Care, the WPAC Standards of Care and Gender Identity Disorder. Second, this section asks how the participant feels about the medical model. A direct challenge to the idea of GID as a mental illness will signal the possibility that the participant rejects the mentally ill label.

While the previous sections all directly relate to labeling theory, section $\mathrm{F}$ allows participants the chance to talk about their thoughts and feelings while experiencing therapy, as well as around the mental health industry as a whole. The section starts by again asking participants to tell a story about their experiences in therapy as it relates to gender. From there participants are asked questions about how well they felt their therapist interacted with them about their gender identity. The questions aim to understand whether or not individuals felt comfort and support at attaining services of the mental health industry while freely expressing their gender variant identity. If the individual felt their identity was not fully supported in the therapy setting, the section looks at methods participants used to cope with this lack of support. The section also asks questions that measure the individual's satisfaction with the therapy they received.

\section{Data Analysis}

Due to the heavy emphasis on theory that structured the research, grounded theory was not utilized. Interviews were transcribed from digital audio recordings. After 
transcription, “issue-focused analysis," as described by Weiss (1994) was utilized. Issue focused analysis focuses on multiple cases, searching for similarities and differences located within similar experiences. Weiss suggests that coding, and refining of these codes, take place multiple times until the researcher feels they have a firm grasp on their data. Initial coding took the form of broad conceptual categories derived from the interview guide:

\section{Gender Identity}

This category contains data about the participant's gender identity both as they currently identify, as well as past identities. Emphasis on noting not only identity but also time allowed for the data to include identity shifts during, before and (when applicable) after therapy.

\section{Societal Perceptions}

This category contains participants self reports of positive and negative reactions that friends, family and others have had to their gender presentation. It also gauges the participants thoughts and feeling about these reactions.

\section{Social Support}

The social support category tracks people and places that the participant feels positively support a transgender identity. This includes family and friends who hold positive attitudes toward transpeople, as well as transgender friends and support groups.

\section{Medical Models}

This category looks at an individual's knowledge of the Harry Benjamin and WPATH Standards of Care, as well as Gender Identity Disorder. It also contains data as to 
participants' reactions to these models, as well as their acceptance or rejection of them.

\section{Experience in Therapy}

Even in the initial coding stage, it became clear that this category really contains three clear subcategories: Before, during, and assessment.

\section{A. Before Therapy}

This category contains the participant's experience with therapy relating to gender before they entered the therapy setting. This data includes reasons for entering therapy, how an individual found their therapist, as well as anecdotal advice received as to how to behave in the therapy setting.

5B. During Therapy

This category looks at the individual's experience while in therapy.

\section{C. Assessment of Therapy}

This category contains assessments the participant made both about their own experience with therapy (and how it could have been improved,) as well as any assessment offered of gender therapy as an institution.

Due to the important element of time in relation to identity in my work, I utilized what Spradley (1979) describes as a schematic diagram in addition to coding. Spradley suggests drawing diagrams that map events over time along with their significance to the participant. Schematic diagrams attempt to make sense of a series of events and how those events relate to or affect each other. Spradley writes that "The final diagram you create is not nearly as important as the process of visualizing the parts of the cultural scene. This thinking process is one of the best strategies for discovering cultural themes" 
(199). My research focuses on changes in identity over time, and schematic design proved useful in helping me to initially visualize these shifts.

In order to diagram identity over time, I utilized a three section timeline which chronologically listed events relating to gender identity before therapy, during therapy and when relevant, after therapy. The result was a diagram which clearly demonstrated when an identity shift occurred, and during what point of the therapy process that shift occurred. Although all diagrams were for my reference only, and thus hand written, figure two is a rendering of the diagram I created after coding Dan's interview. Words shown in bold are time periods of Dan's life, while the words to the right of the time periods are events that relate to his gender identity at that time. Time periods and events are outlined chronologically from top to bottom, with all events before therapy taking place first, events during therapy taking place second, and events after therapy taking place last. 
Figure II. Dan's Gender Identity Timeline

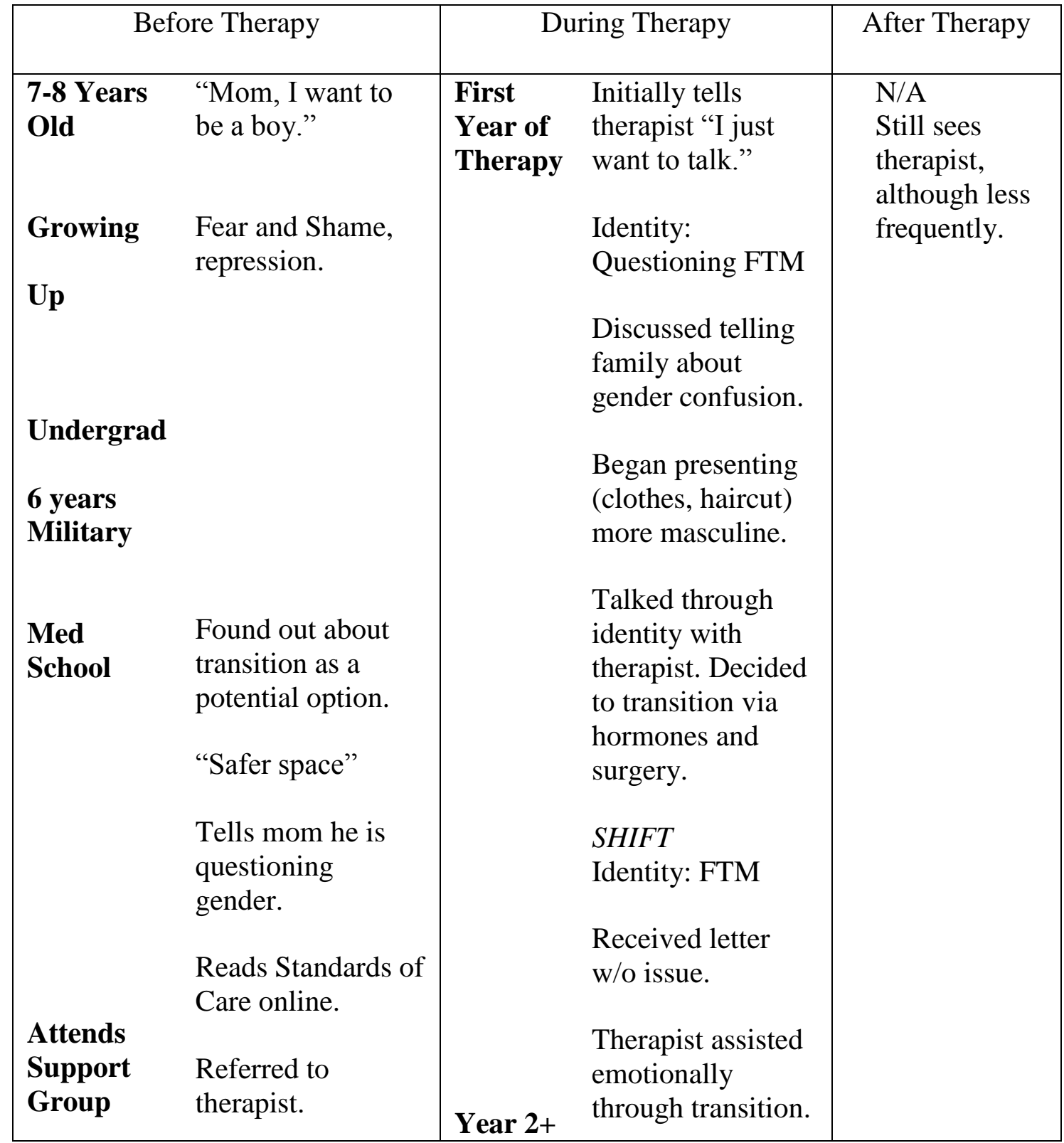




\section{Chapter V}

\section{FINDINGS}

This research used labeling theory to address the relationship between shifts in gender identity and the mental health system, in gender variant individuals. This chapter first looks at identity shift through presenting how participant's labels for themselves, as well as their decisions concerning hormones and surgery, changed during therapy. Next, the chapter examines participant's knowledge of the label of Gender Identity Disorder (GID), as well as whether the label of GID was accepted or rejected. Last, an explanation of identity shift that focuses on participant's motivation for entering therapy is proposed.

\section{Identity Shifts}

\section{Labels}

Participants used a variety of labels to describe their current gender identity. Often the label included acknowledgement of a transgender identity. Four participants (Alex, Beatrice, Clara, and Ace ${ }^{1 *}$ ) use labels for their identity which mention transgender status, yet do not employ the traditional gender categories of male or female. Clara and Ace adopt the term genderqueer, a label used to signify a lack of adherence to the gender binary. Alex also calls himself genderqueer but additionally calls himself a transguy. Beatrice explains his identity choices by explaining that while he identifies as trans, he does not feel the desire to change his birth name.

So that's kind of where I'm at. Going by a traditionally female name and going by "he" pronouns and presenting how I like. And that's that.

\footnotetext{
${ }^{1 *}$ All names of participants presented are pseudonyms. Some participants chose their own pseudonym while others were chosen for them.
} 
Five participants (Joseph, Jack, Jordan, Alex and Dan) label themselves as transgender men with the label transguy, female to male, or FTM. Identifying oneself as transgender did not limit participants from identifying with traditional gender categories. Of the participants who acknowledged transgender identity through their labels, three additionally labeled themselves male.

Both Nate and Mack label themselves as male without reference to a transgender identity. However, when asked to describe his gender, Mack describes feeling genderless at times.

Everybody just kind sees me as this butch, even though I don't really fit into the category because I'm really uncomfortable as far as female bathrooms, male bathrooms- because males think I'm female and vice versa. So it's kind of more like I'm just there, almost like asexual, like I'm just kind of something that doesn't have a gender.

Through context it can be inferred that Mack does not use the word "asexual" in its traditional sense, but rather uses it to describe his gender identity as it relates to others. While he identifies as male, interactions with others cause him to view himself as genderless at times. Mack was the only participant who emphasized societal views of himself when describing his gender identity.

Carl was the only participant who did not identify as transgender or with a gender that was not assigned to them at birth. Carl identified as a butch lesbian, while clearly explaining also feeling gender variant.

I did pretty intense therapy for about two years, focusing on that topic and I kinda settled in the middle of about a 70/30 male female expression in my life. I use the label lesbian, although that feels a little girly to me. Ya know, it just kind of works in my life. 
Carl explains that she feels both male and female and does not fit into the gender binary, which she states she does not believe in.

\section{Identity Shift}

It should be noted that the identity shifts being examined for this study are those that take place during therapy. As gender identity is not always static, especially in transgender individuals, identity shifts took place before entering therapy, and may end up taking place after therapy. All individuals who participated in this study explained at least one, and often more, identity shifts prior to entering therapy. Most notable is a shift between identifying as a cisgender ${ }^{2 *}$ individual and a transgender individual. While shifts in identity can take place throughout an individual's lifetime this study focuses specifically on shifts potentially caused by a label received from a mental health professional, and thus only analyzes identity shifts that occurred during the time the individual was seeing a therapist.

During preparation for this study, as well as initial data analysis, I assumed that identity shift could be measured through a change in identity label. Of twelve participants, only two (Jack and Joseph) changed their identity label while in therapy. Joseph identified as genderqueer while in therapy and shifted to indentifying as an FTM and male. Michael identified as a transperson before therapy and later identified as a transman. While only two of my participants changed the label for their identity while in therapy, it is clear that many more had identity shifts. Through analysis it became clear that tracking identity shifts through identity labels was insufficient.

$2^{2 *}$ Cisgender refers to individuals who identify with the sex and gender they were assigned at birth. 
This may be because of the population in which this study is based. Studying a subgroup of the transgender population who feels (or has felt at one time,) that they do not identify with the gender binary has led me to a population with an overall awareness of gender as a social construction. None of my participants chose to label themselves as transsexual either before, during or after therapy, but instead opted for words like transgender or genderqueer, which allow for more fluidity in definition. Both transgender and genderqueer (as discussed in chapter two) describe groups of gender variant people with a range of identifying characteristics. While the word transsexual most often describes an individual who wishes to transition medically from one sex to another, transgender and genderqueer are umbrella terms which describe many different body types and medical choices. Therefore, a shift in identity can happen to someone who is transgender or genderqueer without the need to change identity labels.

An example of this can be seen in Ace's identity shift. Ace entered and exited therapy with an identity of genderqueer. However, while in therapy Ace made the decision that he would eventually like to receive chest reconstructive surgery. The way that he describes and relates to his body shifted while his identity label, "genderqueer," stayed the same. This is because the term genderqueer covers a wide variety of identities, including those who want hormones and surgery, and those who do not. While I expected a shift from a gender variant identity to that of transsexual in those who decided to medically alter their bodies, that did not happen. Instead, qualifiers were used to explain the identity when asked. Chris identifies as genderqueer, but specifically a genderqueer who desires surgery and not hormones. 
Through analyzing the data I found that the types of identity shifts that occurred in the participants involved not only changes in identity labels, but also the level of confidence in that label, and identity related medical decisions. Level of confidence identity changes were seen in participants (Carl, Dan, Beatrice) who went into therapy questioning their identity and came to a place during therapy where they no longer questioned what they labeled themselves. An example of this would be Carl, who always labeled herself a butch lesbian but questioned whether or not she was transgender.

You know I kinda just settled into a place of, ya know, my body is what it is and I'm happy. If you're looking to hear my two cents on transitioning, it's basically not for me, I don't wanna be a man because men are pigs, and ya know I don't want to be that and I'm enough of a lesbian feminist that that feels weird. I am totally trans supportive, $1000 \%$, it's just not for me. I had to make sure that- this is really what I did in therapy was- Is this my transphobia? I'm gonna take it out, I'm gonna look at it. Am I avoiding the situation? What's going on with this? Shit or get off the pot time. Make up you mind. I decided that I'm good where I'm at and I know that's not the answer that everyone would have to that question.

Carl used her time in therapy to conclude that transitioning from female to male was not something that she desired. She went into therapy as a lesbian who was questioning her identity and decided that she was in fact a lesbian. Beatrice also used his time in therapy to move from questioning to sure of himself.

There was definitely a point where I was identifying as trans but thinking of myself as a problem and wishing that I could just connect to my body in the way that your average cisgender person does. I think in talking with her I kind of came to the realization that, after being asked different questions from her, that it wasn't my brain that was the problem ... At one point I compared myself to a person that thinks that they should have an arm or something like that-because there are people who feel that their arm is wrong and they want to get it amputated. And I think I was kind of saying I wouldn't recommend getting any arms amputated, how can I want chest surgery so badly-like in the same vein if it's similar to that kind of thought like something doesn't belong on you. She really helped me realize that I can still feel connected to my body and still be me, and 
not be like a person who doesn't own their own limbs and just do it differently than most people.

Beatrice expressed initial difficulty in accepting a trans identity due to feeling it was not how he should be. He attributes acceptance of his trans identity to working through his thoughts with his therapist.

In addition to level of confidence in identity, identity shifts could also be seen in the medical signifiers placed after a person's identity label. It became clear through analysis that a person's identity not only consisted of their identity label, but also what they planned to do with their body physically. Nine of my participants (Beatrice, Joseph, Clara, Nate, Michael, Dan, Ace, Jordan,) made medical decisions related to gender while in therapy. Ace made it a point to find a copy of an exercise he and his therapist did together prior to our interview, as it stuck out as particularly important to his therapy experience.

I definitely, like with the surgery, I processed a lot more. Like, if I did this, how would things change? There was one particular thing that my therapist did... She wrote out some questions about thinking about surgery and questions like that... Going through that exercise really helped me to decide that yes, I really want surgery. It may not change certain things, but that's something I really want to do once I have the money.

Clara also expressed finding her therapist helpful in guiding her to a decision about chest reconstruction surgery.

I definitely talked with her about it a lot-About surgery, like top surgery and all of that stuff. And I went and had consults with two different surgeons in the area and one of them requires a letter and the other one doesn't, and so I was happy to hear about that and then, you know, the possibility of needing a letter if I choose to go to the one surgeon and all of that. It was kind of helpful to talk with her about it I guess, mostly I feel like I just needed to say it all out loud and go over all the different things in my head out loud and so having her there was good-She knew how to keep my brain on track, and she knew some good questions to ask me about why I was feeling things and about the different surgeons and all that. 
Therapy provided the space for participants to explore their thoughts about not only how they label their identity, but also what they want to do with their body medically. The purpose of looking at shifts in identity is not in finding out how people label themselves, but how that label affects them moving through the world as a transgender individual. While the way that an individual labels themselves is relevant, in order to get a better understanding of transgender identity body modifications and sureness of identity should also be looked at. Confidence levels and medical decisions have an affect on these individuals' lives, and for that reason must be taken into account.

\section{Knowledge of Medical Models}

Participants were asked about their knowledge of both Gender Identity Disorder (GID) and The Harry Benjamin/WPATH Standards of Care. All participants had a working knowledge of Gender Identity Disorder (GID). When asked if they had ever heard about GID, participants answers ranged from in depth explanations, to shorter working definitions, to opinions about the diagnosis. Offered after being prompted that she was not being tested and that any definition she could provide would be appreciated, Carl explained GID.

Boy I'm not sure I could give a good definition. Just where someone feels that they were born in the wrong body would be the simplest definition.

While Carl was hesitant to provide her answer, she understood in colloquial language the basic criteria for being diagnosed with GID. Carl's definition was the most basic, as other participants gave more in depth explanation in their definition. Nate gave an in depth definition, explaining that GID is a diagnostic tool, as well as adding his opinion about it. 
Yeah, so the Gender Identity Disorder, GID, is in the number 4 [DSM] and then in the number 5 I believe they're proposing it to be Gender Identity Incongruence, and I don't think they have disorder attached to that anymore... And I think there needs to be some kind of diagnostic terminology so people can get covered by insurance. I think calling this a disorder is kind of stigmatizing because I don't feel like this is a disorder...

Nate referenced the DSM when explaining GID, showing that he is at some level aware of practices of mental health professionals. Many of the participants at various points during their interviews also referenced the DSM. Alex provided an in depth explanation of his familiarity with GID.

I've looked at it several times in reference. It's available online so that's all good. The organization changed its name so it's like WPATH or something, so yeah. From what I understand for transguys they require some sort of therapy. Also like living as your preferred gender for a certain amount of time, maybe a year. For surgery you need one letter for top surgery and two letters for genital surgery. One has to be from a PhD, one has to be from a master's or higher. In coming up for the criteria I guess some of the stuff they look for is presence of knowing about your gender difference from a very early age and a strong desire to be "opposite gender." Technically you can't have an intersex condition and be trans. But who knows who's intersex and not? I can't afford to have my chromosomes checked so ya know. There's lots of little stuff.

Participants showed a high level of knowledge of medical models, with all of them able to discuss the topic to some degree. When asked when they first learned about the term, all participants stated that they learned of GID before starting therapy for gender.

\section{Acceptance/Rejection of Mental Illness Label}

Acceptance vs. Rejection

It is important to know whether or not participants had a working knowledge of GID in order to determine whether or not they accepted or rejected that label. The first element of labeling theory that was examined is whether or not acceptance of the label occurred. Labeling theory states that an individual can either accept or reject the mentally 
ill label. Acceptance of a mentally ill label leads to conformity with displayed characteristics expected of that label. Of my participants, nine rejected the label, two neither rejected nor accepted it, and one accepted it. Of the participants who rejected the label, all actively rejected the label throughout their time in therapy. Some individuals may have also rejected the label prior to therapy, which is discussed in more detail in chaper six.

The sole individual who accepted the label of Gender Identity Disorder is Mack.

When asked how he felt about being diagnosed with GID by his therapist Mack said:

I was- normally I don't like therapists or the psychologist thing but I was so happy when she finally put a label on it. It was a huge stress relief because, ya know, outing myself- because I knew I wanted to be male but I didn't say or do anything about it. So I figured the next best thing was butch lesbian, and so I outed [came out as a butch lesbian] to feel a little more comfortable in my skin. But I also, I got commented on it often because I wasn't really somebody that was prideful in the lesbian community. I wouldn't be like woo, look at me, and I wouldn't hang out with a bunch of lesbians. I was actually just the total opposite because everybody that I knew was like out in the bars, and they're like "woah, girls that like girls, girls who kiss girls," and I just, I don't believe any of that. You know? I just wanted to just be off the radar.

Mack expressed relief at the prospect of being diagnosed with GID. He felt his identity as a transman, and specifically not a lesbian, was legitimized by the label. He describes feeling that it made sense that he did not fit in with lesbians, and that being labeled with GID helped him feel that this was legitimate.

Dan had less of a reaction to the concept of GID. In reference to GID, he said:

I know, I think that's what it's technically classified as under the DSM 4. I don't know, I guess that's all-that's our official coding diagnosis but I probably couldn't give you more.

Dan states that he knows what GID is, but does not remember the specific criteria one must meet in order to be diagnosed with GID. He has no judgment of GID, and states that 
it is simply a diagnosis. Dan did not speak of talking to his therapist about GID, and it does not seem to be a part of their dialogue. Instead, it seems that Dan was not particularly affected by GID, and thinks of it as something formal that did not enter into his therapy sessions. It is for these reasons that Dan cannot be said to either reject or accept the label of GID, but is rather neutral. Carl can also be said to be neutral, as she did not explore the concept in therapy and did not feel it applied to her.

The majority of participants actively rejected the label of GID. Rejection of the label took the form of classifying the diagnosis as invalid. While participants understood and clearly stated that their gender was incongruent with society's expectations for their assigned sex, they did not feel that this was something that should be pathologized.

Beatrice speaks of the idea of GID by saying:

I think it contributes to the idea that we are crazy, and I don't really like the word crazy in the first place, but the idea that there is something wrong with out brains. I kind of like the idea that there's something wrong with my body and I value my brain and I think that it's not off, it's just different and I'm a variant of the human condition and that's ok. There's lots of people who are different in lots of different ways and they're not pathologized. Also I think that part of it that makes me feel ok and that it might be changed in the DSM is I think gay used to be in there as well, so now when people say things like, "Oh, you know, gender identity disorder is in the DSM as a mental illness, "I'm like "You know, so was gay and I really don't think that was a mental problem." So it just kind of gives me faith that the medical community could be wrong in their assessment of my brain.

Beatrice mentions the DSM, and states that GID should not be included in it. Joseph follows a similar thought process.

I say it now, I refuse to be diagnosed with Gender Identity Disorder. I don't think it exists. I actually think it's completely- I talked to a transman who's in his $50 \mathrm{~s}$ and a psychologist and he was like, there's no such thing. Gender Identity Disorder indicates you don't know who you are. Most trans people know who they are their whole life-it's body dysphoria, that's what it comes down to. 
Clara mirrors what has been said, again mentioning the DSM without being prompted with such language.

Well I don't think it should be in the DSM. I don't think it should be classified as a mental thing because all of the treatments for it are generally changing physical things on people, not changing your mind about it. I also don't think that it should be classified as a disorder because I don't think there is anything wrong with people who are trans, and disorder kind of feels like it's an illness, like there's something wrong with you.

Acceptance of the label is one of the key elements to labeling theory. Scheff explains that it is due to the acceptance of the label that an individual's behavior begins to conform to what is expected of that label. As this study focuses on labeling within the setting of therapy, it examined whether or not participants accepted or rejected the label of GID in the therapy setting. Nine participants rejected the GID label, two neither rejected nor accepted the label, and one accepted it. The process of labeling theory as outlined by Scheff assumes an acceptance of the mentally ill label. While it was expected that more of the participants would accept the GID label, that is not what the data showed upon analysis. As the majority of participants in my sample rejected the label, it cannot be said whether or not an acceptance of the label of GID would have contributed to identity shift. However, identifying that acceptance of the label of GID is not occurring in the sample does contribute to the field of labeling theory, as it shows that this element of the theory may not apply.

Those who rejected the label of GID did so on the basis that being transgender should not be considered a mental illness. Often referencing the DSM, participants voiced clearly that being transgender and wanting to physically modify one's body to better represent their gender identity did not mean they should be pathologized. Aside from a 
declaration that GID is an invalid diagnosis, there were several techniques individuals utilized to avoid the label of GID.

\section{Methods of Avoidance}

\section{Informed Consent}

Participants utilized three methods to avoid the label of GID. The first, a) Informed Consent (in which participants were provided hormones or surgery without the need for a letter,) allowed participants to completely avoid the label of GID. Other methods that participants utlilized, while not officially avoiding the label, helped them to mentally block the label while using it to access the services they required. These methods include b) Shopping for Therapists (in which participants carefully selected which mental health professional they would see,) and c) Creative Wording and Jumping through Hoops (in which participants worked within the restraints placed upon them by the mental health system.)

Attaining hormones through informed consent was the only way to escape being officially classified. Two of my participants (Noah and Joseph) took advantage of informed consent, while one (Clara) discovered it was a potential option. Joseph describes that he has not needed a letter for his medical transition thus far.

Well what's funny for me about therapy is that I've had chest surgery, I'm on T, I've had a hysterectomy, oopherectomy, the whole shebang. I've done everything but bottom surgery and I have never needed a letter from a therapist for any of it. So I wasn't in therapy to get letters, to get, you know, for the gatekeeping as I call it.

He goes on to describe that the doctor from whom he received his top surgery was unaware of the letter writing process, as she was not familiar with chest reconstruction surgery for transgender patients. 
In fact, when I went to a consultation for my chest surgery I mentioned, like, I can provide a letter from therapy, and then the woman was kind of like, I don't know what you're talking about so I kind of just shut up. I was like, I'm not gonna bring this up and we had what I felt was an informed consent conversation, of, "Do you know this is irreversible, you're gonna have scars you know etcetera, etcetera?" And so therapy was just like a place for me to go and talk about my shifting gender identity.

Joseph's endocrinologist and surgeons did not require a letter. In Joseph's case, he worked with individuals who did not normally treat transpeople, and thus were not familiar with the culture. They were unaware of the usual letter criteria.

Noah also used informed consent, but worked with a clinic that specializes in trans patients. He explains his experience with the informed consent model in detail. While this quotation is lengthy it is included in its entirety due to the value of its detailed description of Noah's experience utilizing informed consent.

So at [Name of Clinic] and a couple other places around the country now, which is pretty darn cool, they believe that if this is something that you want to do you should be able to access the care that you need and want without jumping through too many hoops, which is a huge development. It was just so easy for me. What you do is you go in and you have an intake appointment with the doctor and a full medical history kind of appointment, including gender stuff. Then you tell them what you would like. I said I am here because I would like to start testosterone. They said "Ok, well here is this huge packet of information and you need to take it home with you and read it." So I read this huge thing that was basically a very easy to understand guide to hormones for FtMs that included a long list of effects. It was very clear that also you take a certain degree of risks because they don't know all the effects for sure. So they had hair growth or balding or stopping having your period or all the things that you think of, and then all these other things that you don't think of. Being more careful with your blood pressure and cholesterol and men live less long than women.

Noah goes on to explain his experience after going home and returning to the clinic.

So I read through it all very carefully and I wrote down any questions that I had. I brought it back with me to my next appointment where she went over with me all the questions I had-it was very clear and I took notes. I think it was then that she said, 'Ok do you feel ready to sign the informed consent?' I said yes because I was now informed. So she said ok and then she had to leave the room and a 
specific person had to be in the room while I signed it. It was just a form that said I authorize the people at [Name of Clinic] to teach me how to inject myself with this hormone. It was pretty straight forward and not lawyery or anything. As soon as I did that it was just like ok so- she came back in the room and was like, "All right, so what do you want, how often do you want to do it, do you want to do it in your leg, do you want to do it in your butt? Do you want to do it, do you want someone else to do it, do you want us to do it? Do you want cream? It was just like all of a sudden there was this pharmacy open to me.

The clinic which Noah received hormones from clearly had legal precautions in place, as evidenced by the procedure of signing legal documents. However, Noah was not asked about his gender identity, leaving the reasons behind desired masculinization up to the individual. No permission from a mental health professional is required in order to receive hormones or surgery under an informed consent model.

While both Noah and Joseph were able to avoid needing a letter, both had future plans that would require them to attain a letter from a therapist formally diagnosing them with GID. For Noah, a letter would be needed when he received top surgery. Joseph plans to have bottom surgery.

What I'm struggling with is having had my hysterectomy and then my oopherectomy, which were two separate surgeries, while both technically medically necessary they were not really that. It was just, I lucked out, let's put it that way. And not having needed a top surgery letter or a testosterone letter. I do plan on getting bottom surgery, and the fact that I'm going to need not one, but two letters makes me absolutely bonkers. It infuriates me to every cell in my body. I understand it to an extent. I'm very conflicted by the fact that the surgeon I'm going to go to is transgender and I understand that it's a whole big complicated game and it comes down to malpractice insurance and your lawyers may dictateand the hospitals where you work may dictate things and things like that.

Joseph expresses frustration that he will need a letter for bottom surgery, while admitting he understands the reasoning behind it. While some of my participants have managed to avoid receiving a letter up to this point, all who plan to have future surgeries or attain hormones for the first time (with the exception of possibly Clara, depending on choice of 
surgeon) foresee needing a letter. However, even when a letter is required participants have additional methods for avoiding the label of GID.

Shopping for Therapists

Participants found it important that their therapists hold similar ideas about gender as they did. They understood that there was bureaucracy surrounding their medical choices related to gender, but wanted their therapist to understand the shortcomings of the mental health system in serving transgender individuals. This required that participants shop for a therapist that worked for them. Shopping took two general forms. The first is research. Participants researched therapists before meeting with them in order to assess whether or not they would work well together. Jordan describes using information provided directly by mental health providers to do his research.

Most of the time I would go more by, if I was choosing the therapist, I would go more by generally being queer friendly as opposed to trans friendly and then I would bring it up- like I would bring up that I was trans and ya know depending on how they reacted to that I would either stick with them or go find somebody else. But this time around I actually made a point of looking for someone who would say in their little blurb on the website or something that they were trans friendly and actually genderqueer friendly, or at least conscious of genderqueer people and gender variance and stuff like that.

While some utilized information that came directly from mental health providers, often research took the form of utilizing community resources. Clara describes finding a therapist utilizing both people in the community and the internet.

And I was finally like, I just need someone I can talk to about it. So a friend of mine recommended his therapist to me, and said that she had a lot of trans clients. She wasn't like a gender specialist, but she knew a lot about it and she had been working with the trans community. So I checked her out on the internet and I went and had an appointment. She was really, really great.

Nate describes utilizing similar resources. 
I asked around in the community. I looked at a lot of the trans community resources on the web-I think there's T-Vox and a few other ones that list therapist in your area that are trans friendly. I looked at therapists that were LGBT friendly that took my insurance in the area. I called two of them to find out if they took my insurance and one of them did. I had an initial, one of those intake meetings with her and I liked her so that worked out.

Nate describes the therapists he found as positive and in line with his beliefs about gender. However, he believes that if your therapist isn't a good fit, you should find a new one. When asked to give advice to other transpeople, Nate says:

I would tell them that they- For trying to find a therapist they should look around and ask people they would recommend, people who are in the community who have used a therapist and also look at resources online. Once they find a therapist, make sure they like them. Kind of the therapy thing in general, if you don't like your therapist and don't think you could work with them than it's not going to work. Think about what you want out of the experience. If you just want a letter then you should just ask point blank and make it clear that your only goal is to get a letter-If the therapist isn't ok with that, find another therapist.

While some participants were happy with the therapist they researched and chose,

others felt the need to terminate sessions with their therapist to find a therapist who was a better fit. While Nate did not have any major problems with his therapist, he describes leaving his therapist to find one with a better fit.

I had a space that was safe and non-judgmental. Then I decided that I wanted to see someone with more experience with transpeople because I felt that would be more useful to me because I felt that, really, the main thing that I wanted to figure out and decide about was whether or not I wanted to transition now or in the future or ever and I thought that someone with more experience with transpeople would be able to be a better sounding board.

Nate felt it important to find a therapist that would best suit his needs, and felt

comfortable in doing so. Joseph describes a situation in which he interviewed a potential

therapist by phone and found he did not want to work with her.

She said that she would-she's a clinical psychologist. She said that she would diagnose me with gender identity disorder. That would be a requirement- she was 
letting me know that ahead of time. And I was just like, "Well I don't have that." And she was like, "Well yeah, you're transgender so you do." It was that kind of conversation. And she was so stuck in this teeny tiny box of completely black and white thinking. And I was saying, look I've done it all except for bottom surgery but I think I need a therapist who can deal with other issues in my life. I'm kind of over gender in a lot of ways. We can talk about it, but it's becoming less and less of an issue. And she was just like, if you're trans there's no other thing worth talking about because you have this disorder and it needs all of our time and attention- as if I were like a 7 year old who was saying they were born male bodied saying I want to be a girl. And that's a whole other circumstance and, it's a whole different story and journey. I'm 33 years old, I'm almost 34. I couldn't understand why she was so emphatically-Like... We don't live in the 1950's ya know? Like, the transsexual phenomenon anymore, ya know it's not a phenomenon. It's been proven biological and evolutionary and whatnot. So it's just the weirdest thing, that's why I'm like, I will forever be turned off from quote, unquote gender specialists.

Joseph specifically references stating his desire not to be diagnosed with GID and his potential therapist's resistance to that. While the therapist would have taken him on as a client had he submitted to being diagnosed with GID, Joseph decided he could not work with her and found a therapist whose beliefs about GID were more in line with his own. Creative Wording and Hoop Jumping

After finding a therapist who avoided the use of the label GID in their sessions, participants were realistic about the need to be officially diagnosed. The majority of participants had need, or projected needing in the future, a letter from their therapist which mentioned GID. Participants saw this need for a letter as something bureaucratic that needed to be acquired in order to get what they wanted. Acquiring a letter that references GID can be seen as jumping through hoops, as the participant does not accept the label of GID as truth, but rather goes through the motions in order to get their desired surgeries or medications.

Alex describes experiencing hoop jumping as well as utilizing creative wording. 
The first visit we were just like, so yeah I'm trans as you could probably tell and there's not much to this story, but I have to do this thing for the letter. And she was kind of just like yeah there's not really much to talk about but according to the standards we have to meet four times over a month period or something like that. So we did our four visits and it was fine and she wrote the letter. It was also cool because I didn't have to be $100 \%$ male identified. I brought up the fact that I felt more androgynous or genderqueer but I felt that I should physically be on the guy side more that the girl side and that's why I wanted to take T. And actually in my letter it actually says meets the criteria for gender identity disorder instead of has been diagnosed with. Even though that's a small technicality I kind of feel good about that because I hate having the diagnosis for gender identity disorder because I hate the idea that you have to be diagnosed with a mental disorder in order to do what you want with your own body.

Alex made it clear from the beginning of his therapy session that he was genderqueer and wanted to physically transition to a more male appearing body. He also mentions that the wording of his letter does not follow traditional protocol.

Joseph also listed creative wording in the letter as a way of subtly subverting the mental health system's requirements and avoiding the label of GID.

I can use, like Dr. Bower's allows language such as, she uses WPATH now... but she'll allow "meets the criteria for" rather than "has been diagnosed with" gender identity disorder, so she's good about that. So I've had to do some hoop jumping recently that I hated to have to do but needed for my birth certificate. So it's like, ok, it sucks but it's not that bad, if I have to do some hoop jumping, you know.

Noah's therapist took creative wording a step further, releasing the power over the letter writing process.

What I did is I brought it up to my therapist and she said-How about you write it and we talk about it and you know edit it how we see fit and then we can both sign it? And I said that that sounded great. So I ended up writing a letter myself and doing exactly that.

It is clear that for Alex, Joseph and Noah, the wording of their letter held significance.

All three letters avoided containing the phrase "has been diagnosed with," thus not officially declaring a diagnosis of GID. 


\section{Acceptance/Rejection and Social Support}

Taking into account Peggy Thoits' work on self labeling theory led to looking at social support in relation to acceptance or rejection of a mentally ill label. Thoits' work details that strong social supports from community members can lead a participant to acceptance or rejection of the mental illness label, depending on whether the community rejects or accepts the label. Participants were asked where they drew social support from, as well as whether or not they felt there were individuals in their life who were not supportive. The majority of participants reported both negative and positive social support. All participants but two (Michael and Clara) reported that they had experienced negative social support. Of the negative experiences, some were temporary and were reconciled, while others persisted.

Negative social support was most often reported from family members, not friends. Both Carl and Joseph experienced tension between transition and their partners. Carl's partner set an ultimatum between her and transition.

I've been with my partner for 17 years and when I first started talking about this she said, "If you transition I can't be with you anymore." And, ya know I get thatshe's a lesbian separatist on that side of the scale and I get that and ya know it scared the crap outta me. So I decided I had to make up my mind and really make a choice. Now I feel like I'm on both feet, totally planted where I need to be and I'm in a really good place.

Carl knew that making a decision to physically transition would cause her to lose her partner and the life they had built together. Joseph's partner initially was not in support of his transition, but later changed her mind. It was not until his partner supported him that he decided to physically transition to male.

Immediate was, my wife one day. We lived apart for five months because she stayed in LA to finish her school year. Something about that allowed her to come 
to a point where she gave me the go ahead finally and I was, you know, and I practically had a needle in my leg the next minute. So initially it was my partner's support which was the first and foremost support, you know, the most important.

Joseph describes partner support as something that was a high priority for him. He waited until his partner was ready before he began hormonal transition.

Like Joseph, Nate also delayed a part of his transition due to his family. He describes his coming out in the following way:

I think maybe end of maybe either Christmas of sophomore or Christmas of junior year [I came out] as genderqueer slash questioning I think I'm trans and they um, it was right before I left to go back to school and they took it ok but I certainly wouldn't say they took it well. And apparently at that time even though they appeared supportive they thought it was just a phase and hoped that that was what it was. The next year they came down to visit for a day or two to see me in a fencing competition. Around that time we also had a kind of family therapy meeting with my current gender therapist at the time that went ok, but it didn't really help them or me. I currently I don't consider them supportive at all and I mean I think they would be somewhat tolerant but that's purely because I have not started any really significant medical changes.

Since that time Nate's parents have continued not to show support for his identity. Nate

expresses that religion plays a part in his parent's feelings about his trans identity.

Beatrice also talks about religion when expressing his parent's disapproval.

I would say that my parents are not supportive of my gender identity. When I came out as liking girls they said, "and?" and I said and nothing, that's the end of my sentence. And they said, we thought you were gonna tell us that you were a boy and we couldn't have taken that. That was just kind of really not supportive like, uh, questioning gender. They weren't supportive obviously when they yelled at me for binding and didn't really have an open conversation with me about it. And they weren't supportive saying I can't dress the way I want to dress or cut my hair the way I wanna cut my hair or wear the underwear I want. Just not being open to my gender expression even if I wasn't identifying as trans out loud to them they weren't supportive of that. They also say things like transpeople's prayers don't go to god and telling me that trans people go down the wrong path and I need to go down the right path and they don't want to see me do anything bad and blah blah blah. Oh and that they would rip me out of college if I was to do anything translike, whatever that means- which I take as a serious threat. 
Friends were less of an issue of negative social support among participants. Only

one participant, Carl, describes losing friends over their gender identity.

Have I lost friends because of this transition? I have. And one of them was a set of friends that was kind of separate to this web so it's been a little awkward. It was just somebody that just, when I stepped into my authentic self, she had a bad reaction-so, we'll just leave it at that. She couldn't get behind it. I keep wondering what I did. What did I do to make somebody not want to be my friend anymore?

While Carl lost friends due to her identity, the majority of issues participants reported about friends were based on lack of positive support, not presence of negative support. Feeling not understood or not fully supported by friends was brought up as a difficulty by some.

Positive Social Support

Seven participants were not having problems with their families at the time of their interviews. Of the seven, two (Dan and Joseph) had initial problems with family members that were eventually worked out. When asked about social support, only one participant (Dan) spoke of a supportive relative and only two (Mack, Beatrice) spoke of supportive partners. More often individuals drew support from friends. The queer identity or sexuality of these friends was often used as a qualifier when describing social support. All but one participant (Mack) described having queer or trans allies who they felt were supportive of their identity. Clara describes being immersed in the queer community.

I would say that my close friends are pretty much all queer or trans in one way or another. They all get it, they all see me, you know, the way that I want to be seen.

Alex similarly reported primarily associating with queer people.

At that point I started indentifying as trans and started going by Alex instead of my birth name which is just with an ["is"] so it wasn't that big of a change. Everybody, since I kind of have mostly queer friends and run in queer circles and basically won't do anything that isn't queer friendly, it wasn't that big of a deal for 
my friends. Even the ones who didn't totally understand the gender thing they knew that it was in the queer spectrum so it wasn't like this really big identity crisis within the queer community or anything, at least the people that I knew. So I started slowly using male pronouns but it was mostly my best friend at the time who kept using male pronouns and I was kind of like, whatever I don't care either way.

Participants also drew support from trans support groups. Six participants

reported attending support groups. Dan describes his support group as the first step he

took toward accepting a trans identity.

I put it off for like a year just thinking about it and then one day-we have, across our list serve, the medschool one, a male to female transgender in the class behind me who is totally out and just, wow, she's amazing-and she sent out an email to the listserve about transgender awareness week. Under there was a blurb about this transgender support group called Desert Boys. I thought I hope I open this email and I hope I missed this meeting so I don't have to do anything, but sure enough it was that evening. I was such a chicken I asked a friend to go with me even just to go into the front door of our LGBT center in Arizona, it's called [name of group], it's amazing. I was even afraid to go in the front door, but when I did, gosh, I met our community, and I guess the rest is history.

Of the twelve participants, Mack is the only person who describes not being exposed to a gender variant community. When asked if he knew any transgender individuals, he says:

I haven 't, I'm still pretty new to the whole trans thing to begin with so I haven't really found any trans communities here yet-I haven't really had a chance to look. As far as North Dakota I was told by my therapist that I went to that there was a support group every third Thursday of the month, but that was like four hours away. The place that I lived if you happened to come across somebody who happened to be talking about it and they decided to say, "Oh, by the way, I'm transgender would you like to talk?" that's about the luck about it.

When probed as to whether or not he had met any transpeople through coincidence, he stated that he hadn't. The only transperson Mack had ever talked to was an older transwoman who he spoke to over the phone once. Location and resources were a barrier to Mack's connection to the transgender community, which he desires to be a part of. Not 
being a part of a transgender community means Mack lacks social support for a gender variant identity.

Acceptance/Rejection and Social Support

Peggy Thoits explains that social support may play a role in an individual's ability to reject a label of mental illness. She cites a specific type of support, that which comes from a community of similarly strained individuals, as beneficial in avoiding a mentally ill label. Of the 9 participants who rejected the label of GID, all had social support from a queer or trans community. Support from family and partners varied considerably among those who rejected the label of GID. The one participant who accepted the label of GID had no ties to the trans community, and very few (if any) ties to the queer community. While the sample size is small, Thoits' ideas about social support and rejection of a mental illness label are supported.

\section{Potential Reasons for Identity Shift}

Acceptance/Rejection and Identity Shift

This research applies labeling theory to to transgender individuals and the label of Gender Identity Disorder (GID). Looking at the framework that Thomas Scheff provides for labeling theory of mental illness, a pivotal element of labeling theory is the acceptance or rejection of the mentally ill label. In the case of transgender individuals, the mentally ill label is GID. According to Scheff, after being labeled an individual can either accept or reject the mentally ill label. If the individual accepts the mentally ill label, the individual then conforms to characteristics that apply to that label. An internalization of the label of GID could possibly manifest in a change in identity. 
This research looked at whether acceptance of GID could potentially lead to a shift in identity in gender variant individuals. No link was found between participant's acceptance or rejection of GID and identity shift. Only one participant, Mack, accepted the label of GID. However, Mack saw no shift in identity while in gender therapy. While the majority of participants (nine) did see a shift in identity while going to therapy, those participants either rejected (seven) or neither accepted nor rejected (two) the label of gender identity disorder. If internalization of GID were responsible for a shift in identity it could be expected that some of the participants who saw an identity shift would have accepted the GID label. In the small sample of this study there is no support for the idea that identity shift is influenced by an acceptance of the GID label.

\section{Motivation for Therapy and Identity Shift}

While labeling theory provided the framework for this research, it became clear that stepping back from labeling theory may yield additional possibilities when looking at identity shifts during therapy. As the majority of participants did see a shift in their identity during therapy, it seems plausible that there may be a connection between therapy and identity shift. As stated in previous chapters, mental health practitioners act as gatekeepers to medical changes an individual may want to make to their primary or secondary sex characteristics. It is necessary for most individuals who want to change their sex characteristics to receive permission to do so in the form of a letter. All participants who desired medical transition in some form stated that they had previously needed, or would in the future need a letter for at least one aspect of their medical transition. 
However, a letter was not the only reason participants cited for receiving gender therapy. Participants can be grouped into two categories, those who enter therapy to process their identity (gender explorers) and those that enter therapy solely for a letter (key seekers.) The majority of participants were gender explorers. Participants utilized therapy in order to help them decide what they wanted to label their identity and what medical modifications, if any, they wanted to pursue. Clara describes feeling the need to talk to a mental health professional about gender.

I first started thinking about going into therapy for gender when I realized that it was too much for me to handle on my own. It was after I came out to my family, but it was still maybe two years ago that I started thinking about it. It was, like I came out to my family and they were kind of supportive in their own way, but they didn't know anything about it. And my friends were all supportive, and I could kind of talk to them about it, but they didn't have the skills to help me figure out how to deal with certain things or approach certain things, or helping me come out to other people and all that stuff. I'd been keeping kind of like a gender diary or something, just kind of writing down everything so that it wouldn't explode in my brain from having too much stuff in there. And I was finally like, I just need someone I can talk to about it.

Clara did not have an end goal of a letter in mind, but wanted to discuss gender with someone other than her friends and family. Dan similarly wanted to talk about his confusion surrounding his gender.

I told her at the beginning I just wanted to talk about everything. Not with an end goal of hormones or surgery, but lets kind of deal with what's going on that has been hidden away for a long time.

Clara, Dan and seven additional participants used therapy as a means to talk about their gender identity. Ace describes therapy as a place where he could explore the idea of surgery.

I definitely, like with the surgery, I processed a lot more. Like, if I did this, how would things change? There was one particular thing that my therapist did... She 
wrote out some questions about thinking about surgery and questions like that... Going through that exercise really helped me to decide that yes, I really want surgery. It may not change certain things, but that's something I really want to do once I have the money.

Through an exercise with his therapist Ace was able to decide that in the future top surgery is something that he desires.

Nine individuals expressed feeling a desire to sort through their feelings about gender with their therapist, and have therefore been categorized as gender explorers. Three individuals entered therapy with the sole intention of getting a letter. These individuals have been categorized as key seekers. Alex explains that he went to therapy because informed consent was not accessible to him.

The first step was finding a therapist because we had, this was at [city] Florida, the one endocrinologist in town who would give T to trans guys required a letter and I was like, well, that's kind of lame so I contacted my endocrinologist back home that was covered through my insurance and they were like, well we need a letter to. So I was like, ok, I guess I better do this letter thing. So I found a therapist, somebody that a lot of other transguys in the area had gone to see, in that two years that I was out as trans I met a lot of other trans guys in the community, not only just at school but also just people who lived in [city] which was really cool.

Nate and Alex had similar experiences, entering therapy primarily to obtain a letter.

Upon analysis it became clear that there is a correlation between identity shift during therapy and the participant's motivation for therapy. As apparent in Table 1, all participants who had an identity shift during therapy were explorers, while all those who had no shift were key seekers. This suggests that there is a connection between motivation for entering therapy and identity shift during therapy. 
To better understand this it is necessary to look at what an identity shift for participants entailed. As explained previously, identity shift took the form of moving from being unsure of identity (whether that be what an individual called themselves or what body modification an individual desired,) to sure of that identity. Keeping that in mind, it makes chronological sense that Explorers had identity shifts during therapy and Key Seekers did not. For Key Seekers, a shift in identity occurred prior to entering the therapy setting. Key seekers moved from a place of questioning their identity to being sure of their identity without the help of a therapist. Key Seekers were sure of their identity prior to therapy and did not go into therapy seeking guidance. On the other hand, Explorers looked for and found guidance about their gender identity from their therapists. While it cannot be said that explorers "planned" to have a shift in identity during therapy, their desire to come to a conclusion about their gender through the aid of a therapist meant a shift was possible. In all cases explorers reached the conclusions they were looking for, thus resulting in an identity shift. Therefore, the data suggests that therapy may have played a part in participant's identity shift. What the data cannot say is whether participants would have come to similar conclusions had they not chosen the setting of therapy as a place to explore their gender identity. 
Table I. Description of Research

\begin{tabular}{|c|c|c|c|c|c|c|c|}
\hline \# & Name & $\begin{array}{l}\text { Identity Prior } \\
\text { to Therapy }\end{array}$ & Current Identity & $\begin{array}{l}\text { Identity } \\
\text { Shift? }\end{array}$ & $\begin{array}{l}\text { Accept } \\
\text { Or } \\
\text { Reject? }\end{array}$ & $\begin{array}{c}\text { Queer/ } \\
\text { Trans } \\
\text { Support? }\end{array}$ & $\begin{array}{l}\text { Key Seeker } \\
\text { vs Explorer }\end{array}$ \\
\hline 1 & Jack & $\begin{array}{l}\text { Transperson, } \\
\text { No-ho, } \\
\text { Questioning } \\
\text { surgery }\end{array}$ & $\begin{array}{l}\text { Transmale, } \\
\text { Plans for surgery, } \\
\text { On hormones }\end{array}$ & Yes & Reject & Yes & Explorer \\
\hline 2 & Carl & $\begin{array}{l}\text { Butch lesbian, } \\
\text { Questioning } \\
\text { Trans Identity }\end{array}$ & $\begin{array}{l}\text { Butch lesbian, } \\
\text { No longer } \\
\text { questioning } \\
\text { identity }\end{array}$ & Yes & Neither & No & Explorer \\
\hline 3 & Mack & $\begin{array}{c}\text { Male, } \\
\text { Person with } \\
\text { body } \\
\text { dysphoria } \\
\end{array}$ & $\begin{array}{c}\text { Male, } \\
\text { Person with body } \\
\text { dysphoria }\end{array}$ & No & Accept & No & Key Seeker \\
\hline 4 & Beatrice & $\begin{array}{l}\text { Trans with } \\
\text { male } \\
\text { pronouns, } \\
\text { Struggling } \\
\text { with identity }\end{array}$ & $\begin{array}{l}\text { Trans with male } \\
\text { pronouns, } \\
\text { Accepting of trans } \\
\text { identity, } \\
\text { Plans for surgery }\end{array}$ & Yes & Reject & Yes & Explorer \\
\hline 5 & Clara & $\begin{array}{l}\text { Genderqueer, } \\
\text { Questioning } \\
\text { surgery }\end{array}$ & $\begin{array}{l}\text { Genderqueer with } \\
\text { Plans for top } \\
\text { surgery }\end{array}$ & Yes & Reject & Yes & Explorer \\
\hline 6 & Joseph & $\begin{array}{c}\text { Trans- } \\
\text { genderqueer, } \\
\text { Genderqueer }\end{array}$ & Ftm, male & Yes & Reject & Yes & Explorer \\
\hline 7 & Nate & Male & Male & No & Reject & Yes & Key Seeker \\
\hline 8 & Ace & $\begin{array}{c}\text { Genderqueer, } \\
\text { Questioning } \\
\text { surgery }\end{array}$ & $\begin{array}{l}\text { Genderqueer, } \\
\text { Plans for surgery }\end{array}$ & Yes & Reject & Yes & Explorer \\
\hline 9 & Noah & $\begin{array}{c}\text { Genderqueer, } \\
\text { questioning } \\
\text { Medical } \\
\text { changes } \\
\end{array}$ & $\begin{array}{c}\text { Genderqueer, } \\
\text { Plans } \\
\text { for surgery }\end{array}$ & Yes & Reject & Yes & Explorer \\
\hline 10 & Dan & $\begin{array}{c}\text { Questioning } \\
\text { female to } \\
\text { male, } \\
\text { transgender }\end{array}$ & $\begin{array}{l}\text { Female to male, } \\
\text { transgender }\end{array}$ & Yes & Neither & Yes & Explorer \\
\hline 11 & Jordan & $\begin{array}{l}\text { Questioning, } \\
\text { boy }\end{array}$ & Male genderqueer & Yes & Reject & Yes & Explorer \\
\hline 12 & Alex & $\begin{array}{l}\text { Genderqueer } \\
\text { Trans Guy }\end{array}$ & $\begin{array}{l}\text { Genderqueer } \\
\text { Trans Guy }\end{array}$ & No & Reject & Yes & Key Seeker \\
\hline
\end{tabular}




\section{Chapter VI}

\section{Discussion}

This exploratory study utilized key elements of labeling theory to explore the question:

What is the relationship between individuals participating in gender therapy and the formation of gender identity among gender variant individuals?

Chapter six discusses the research in relation to labeling theory. It explains where labeling theory may apply to the research, as well as elements of the theory that do not apply. The chapter also suggests areas that if further explored may add to a better understanding of the labeling process. The suggestions for future research in this chapter include ways in which these new potential aspects of labeling theory should be explored, as well as further research into transgender mental healthcare not related to labeling theory. This chapter also contains desires participants held for changes in their mental healthcare.

\section{Labeling Theory}

This study utilized three key elements of labeling theory, (1) Initial labeling process, (2) Acceptance/Rejection and (3) Identity Shift, to explore the relationship between gender therapy and identity shift in gender variant individuals. The first element, Initial labeling, looked at the labeling process. Thomas Scheff explains that labeling theory starts with a behavior. That behavior is then deemed deviant and thus labeled a 
mental illness. This study focused on labeling within the therapy setting, and thus looked at labeling between mental health professionals and their clients. The initial label then would be that of the label of mental illness given from the mental health professional to their client.

The second element analyzed was acceptance and rejection. Scheff explains that after being labeled, the labeled individual can then either accept or reject the label of mental illness. Acceptance or rejection for this study applies to whether or not the participant accepted the label of Gender Identity Disorder (GID). The third element of labeling theory being explored is identity shift. Scheff explains that accepting the label of mental illness causes the individual to internalize that label, thus creating a shift in identity. This study looked at whether an identity shift took place during therapy, as well as why that shift may have occurred. While shifts in gender identity can happen at any point during an individual's life, this study chose to focus on shifts during gender therapy in order to explore the idea that diagnosis of GID from a mental health professional may play a specific role in identity shift.

This study used the initial labeling/acceptance or rejection/identity shift model to look at gender variant individual's experiences with their gender identities while undergoing gender therapy. In this case, the deviant behavior is identifying and behaving in ways society deems incongruent with one's assigned sex. This behavior is then labeled as GID by a mental health professional. The individual labeled with GID could either accept or reject the label, with potentially varying results in identity shift. 


\section{The Initial Labeling Process}

\section{Power and Avoidance}

As the focus of this study centered within the therapy setting, the label given by the mental health professional to the client was initially examined. The source of the label of GID for participants proved more complex than this. Through shopping for therapists participants avoided the label of GID by choosing therapists who would not label them. Therefore, in most cases there was no direct source of the GID label through the mental health professional. The ability to avoid the label of GID through therapist cooperation may set this label apart from other mental illness labels due to the comparative ease of avoiding the label.

However, the power of the individual to avoid the label of GID must be looked at in terms of both financial and social power. The ability of an individual to choose from multiple therapists rests on both their financial state and medical insurance status. Shopping for a therapist that aligns with ones political beliefs about gender was an option for all individuals who successfully rejected the label. Furthermore, the one individual who accepted the label felt he did not have the financial ability to choose a new therapist. This means that it is possible that the ability to escape a label may be dependant on an individual's financial means.

The sample also had high levels of social support. As discussed previously, the presence of social support in the form of transgender support groups and friend groups that identified as queer was high in the sample. Thoits description of self labeling suggests that higher levels of social support lead to an ability to normalize deviant behavior and thus reject the label of mental illness. All of the individuals in my sample 
who rejected the GID diagnosis had social support, while the one individual who rejected the label had none. While the individual who accepted the label expressed desire to attend transgender support groups and meet queer friends, he cited money and location as a barrier to doing so.

The heavy concentration of power in the sample may be the result of my invitation to participate. I may have relied too heavily on a self identification with the "gender variant" label. However, it may be that those with higher levels of education are more likely to be a part of communities that accept terms like "genderqueer" or "gender fluid." This does not mean that gender variant individuals, as defined as "not feeling fully male or female," do not exist in communities outside higher education. Were I to do this study again, I would sample utilizing a request for participants that called for all people who self identify as transgender to contact me. I would then send them a brief survey designed to determine whether or not they are gender variant. From the respondents who were gender variant, I would randomly select a group to interview. Had I taken these extra steps and sampled for people who self-identify as transgender, but not necessarily gender variant, I may have received a higher range of income and education, which may have resulted in more cases of acceptance of the GID label.

The monetary and social capital of the participants of this study creates a unique situation for labeling theory. Labeling theory supports the idea that individuals with power (in this case mental health professionals,) have the power to label those with less power (transgender people) thus having an affect on their identity and behavior. However, the data collected in this study poses an interesting variation to the model of labeling theory. The individuals in this study who were initially assumed to be labeled in 
fact avoided the label of GID due to their own power. The methods of avoidance of the GID label explained earlier rely heavily on resources not equally shared by the American public.

The level of avoidance attained by the relatively privileged sample not only applies to labeling theory but contributes to it. This study indicated that the power of the individual plays a heavy role in their ability to avoid a label from a mental health professional. Further research that involves more comparison between similar groups with varying levels of capital may shed additional light on the correlation between power and ability to resist a label.

Some labeling theorists may argue that the participants in this study were not labeled at all. While participants did avoid being labeled, they had to make a conscious effort to do so. Furthermore, while their power allowed them to avoid the label from their personal mental health provider they were aware that the label existed and could be applied to them. This awareness came in part due to the need for a letter stating a GID diagnosis. It was understood by both participant and therapist that the letter was necessary to obtain the services participants desired. Participants acknowledged that the need for a letter was beyond their control or the control of their therapist.

It was clear that the diagnosis of GID, while not present in the therapist office, still existed. I propose that a distinction can be made between the mental health provider and the mental health system. In the case of this study, many participants felt that their mental health providers did not feel the need to diagnose them with GID, yet an official diagnosis was necessary in order to modify their bodies. Participants were able to escape being labeled interpersonally, yet were officially labeled with GID. Individual therapists 
were in control of interpersonal labeling while guidelines put forward by the transgender medical system made official diagnosis necessary.

Labeling theory makes no distinction between these distinct sources for labels. However, the source of the label could have an effect on internalization of the label and identity shift. This study examined the label source at the therapist level. Studying the source of the label could also give insight into why and how a label may affect an individual's identity. It is possible that the relationship between therapist and patient may provide a different level of internalization than a label from the larger mental health system. It may also be true that as the therapist is the direct link between the mental health system and the individual, therapists play an important role in relaying mental illness labels and the messages attached to them. Through participants finding therapists who actively delegitimize the necessity for the GID label likely lessens the internalization for the GID label and thus may lessen or completely eradicate any identity shift the label may have otherwise facilitated. Future study is necessary to examine a hierarchy of sources in labeling and the power varying sources have on an individual's identity.

\section{Acceptance or Rejection}

\section{Source of Rejection}

While Thoits explains that in self labeling theory the peer group can be an encouraging source in adopting a label, she also says that a group can be helpful in rejecting a label. This portion of self labeling theory is reflected in the data. All nine participants who rejected the label of GID felt they had support from within the gender variant community. Queer and transgender friends, as well as transgender support groups were cited as sources of support for participant's gender variant identity. In all 
participants who had support the support was present prior to therapy. While it cannot be said with certainty that participant's community involvement led them to rejection of the GID label, the data shows that this is a possibility.

\section{Official vs. Interpersonal Rejection and Acceptance}

Of the participants in this study, it was determined that nine rejected the label of GID, two neither accepted nor rejected the label, and one accepted the label. During coding it was necessary to decide what constitutes acceptance and rejection. Acceptance was coded as an individual stating that they felt they were correctly diagnosed with GID, while rejection was coded as an individual either stating they did not feel they as an individual should be diagnosed with GID, or that they believed GID was an invalid diagnosis.

The individual who accepted the label of GID clearly took the label his therapist gave him as legitimate. Niether of the two participants who did not accept or reject the label of GID came into contact with the label of GID in the therapy setting. One of these individuals decided they did not desire transition, and thus never met the official criteria for GID. The second individual met the criteria and transitioned, yet never needed a letter and was not labeled by his therapist.

The individuals who rejected the label of GID did so through clearly stating their objection to the existence of the label. Participants who rejected the label stated that they did not feel that being transgender should be considered a mental illness. Participants felt it was important that their therapist not label them with GID, and desired (and found) therapists who would not label them. 
In coding categories of acceptance and rejection it became clear early on that a distinction could be made based on the source of the label (see Power and Avoidance.) While this project focuses on the source at the level of the mental health practitioner, the transgender medical system as a whole is also a source of the label. While participants felt that they were able to escape the label of GID in the therapist's office, they still needed to officially be labeled with GID in order to receive medical services. Of the participants who desired hormones or surgery, none could escape the necessity of being officially labeled through a letter.

The distinction between unofficial and official labeling is unique to situations in which the mental health provider is deemed a gatekeeper to medical services. While participants reported feeling comfortable with their therapist's views about gender, the therapist was still in a position of power whether or not they desired to be. Transgender healthcare related to body modifications is, for the most part, only accessible via diagnosis of GID through a mental health professional. In order to provide their patients access to services, mental health professionals needed to officially diagnose them with GID, even if they had previously kept that diagnosis out of the therapy setting. Future analysis of the difference between unofficial vs. official diagnosis may prove helpful in analyzing how labeling affects identity.

\section{Preemptive Rejection}

As discussed earlier, labeling theory is presented by Scheff as a linear model. In this model, the individual is labeled as mentally ill and then has the choice to either reject or accept the mental illness label. However, participants in this study were aware of the label of GID and its possibility to be applied to them before they entered the therapy 
setting. Knowledge of the label prior to entering therapy leads to the ability to hold an opinion about the label prior to therapy. In this case the opinion can be reflected in the participants desire to reject the label of GID.

Evidence of participant's desire prior to entering therapy not to be labeled as mentally ill was reflected in their methods of avoidance. Informed consent allowed some participants to access hormones or surgery without being diagnosed with GID, thus avoiding the label through removing the mental health provider's and mental health system's role in access. Shopping for Therapists was also conducted before entering the therapy setting. Participants researched their therapists online and through their community in order to avoid a therapist that would label them with GID.

While Scheff presents the acceptance or rejection of the label as occurring after the individual has been labeled as mentally ill by the mental health professional, he does not explore the possibility of rejection prior to entering therapy. This research may be unique due to the gatekeeping nature of the mental health system to transgender body modifications. While individuals seeking cross sex body modifications need permission in the form of a tangible diagnosis (the letter), most groups of people who have the potential to be diagnosed with a mental illness do not seek that diagnosis as a mean to a life the medical system is actively blocking them from. Transgender individuals are thus more likely to go into therapy with prior knowledge of their diagnosis, and thus a premeditated opinion of that diagnosis. This premeditated opinion on the diagnosis of GID, if negative, is what makes avoidance through shopping for therapists a reality. Future focus on the timing of the rejection of a label may contribute to a better understanding of the process of labeling. 
As explained in Chapter V, almost all (nine of the twelve) participants rejected the label of GID. In the participants of this study, rejection of the label of GID was not an indicator of whether or not the participant's identity would shift. Had the data supported the possibility that labeling theory can be applied to gender variant individual's in gender therapy, those who rejected the label of GID would be expected not to have a shift in gender identity during gender therapy. A shift in identity within rejecters shows that factors other than internalized pathologization may play a role in shifting identities of gender variant individuals.

While the data of this study does not overtly support labeling theory, it should be recognized that this is a small exploratory study. The data indicates a structure in place in which transgender individuals are regularly labeled with GID, yet the majority of the sample was able to avoid this label. Preemptive rejection and methods of avoidance of GID were not originally anticipated when designing this study. The power gender variant individuals held to reject the label enabled participants to side step the process and not be labeled. This does not mean that this study does not support labeling theory, but rather that those with enough capital may in some cases be able to escape being labeled. Labeling theory is most likely applicable to gender variant individual's gender identity. Transgender people as a whole hold little power in American society, with very high rates of death due to suicide and murder, as well as high unemployment and homelessness. (Clements-Noelle et al. 2006, Grant et al. 2010.) By choosing to focus on gender variant individuals instead of the transgender population as a whole this sample was more privileged than the transgender population as a whole. Further research into 
labeling theory and the transgender population is necessary, and is explained in detail in the Suggestions for Future Research section of this chapter.

\section{Desire for Changes in Mental Health Care}

While this project focused heavily on gender variant individual's identities while participating in gender therapy, it also served as an opportunity for those individuals to voice changes they would like to see happen within the mental health system. Participants were asked what their therapists could have done to make their experiences better. While some responses did not focus on the theme of gender, the majority of responses applied specifically to gender therapy. Participants desired that mental health providers be removed from the role of gatekeeper while being further educated about transgender identity.

Therapy vs. Gatekeeping

Through reviewing the feeling of participants about being labeled with GID, as well as frustrations with need for a letter, I suggest that the most logical solution to this problem is a separation between therapy for transgender people and medical services for transgender people. Throughout this work, participant's desire to avoid the label of GID and simultaneous need to be officially labeled with GID have been chronicled.

Participants face the reality that in order to get the services they require they must officially be labeled, yet many would prefer a better option. Nate describes his desire for therapy and access to medical services to be separated in the following way:

I don't think that therapy should be a gatekeeping, letter acquiring experience. I really like the informed consent model, where they're like, "Ok, are you mentally competent? Do you know what hormones will do to you, both good and bad? Ok, you're mentally competent, you're informed, therefore you can get consent and that's done." Whereas, the gatekeeping model- "Are you mentally competent? Are 
you trans? Do you know what the hormones will do to you? Um, ok I'm going to recommend that..." I feel that's a really kind of, I don't know... I think it puts the patient... It devalues their knowledge of themselves. I mean, yeah, there are parts where it's really good and therapy can be really good for a transperson who's questioning their gender and figuring things out, but I think if your end goal is simply just a letter you should find someone ok with that.

He clearly describes that while it may be beneficial for some individuals to receive therapy in regard to their gender identity, he feels this should be separated from the ability to access a physical transition.

While the majority of participants were critical of the role the mental health system plays in access to body modifications for transgender individuals, no individual stated that they were against therapy as a whole. Four participants, (Jack, Beatrice, Joseph and Carl) attended therapy for additional reasons than gender. The majority of participants were explorers, and went into therapy not exclusively with the goal of attaining a letter, but with the desire to talk with their therapists about their gender identities. As described in detail in chapter five, nine participants rejected the label of GID, and only one accepted it. Even those who desired to work through their feeling about gender rejected being labeled with GID.

\section{Education of Mental Health Providers}

While some participants were happy with the amount of knowledge their therapists held about gender, others wished that their therapists were more knowledgeable. Nate particularly had a hard time with a previous therapist that his parents chose for him.

She really needs to know more about trans issues to be able to do her job well. And more about how religion and transpeople are not at odds with each other. 
There are resources, positive resources for transpeople and religion and she should have known about those and been able to offer them to me and my parents, rather than me having to find them for myself. Or rather than having my friend and kind of mentor who's trans and studying to be a pastor in seminary where she got all of these resources. But she was just, she needs to be more knowledgeable in order to be able to work with a trans client in that sort of setting.

Nate felt that in order to effectively work with transpeople his therapist should have been more knowledgeable about transgender issues. Clara describes what a good therapist is in the following way:

A good therapist, I dunno, I guess is someone whose had a lot of experience working with trans people, or non-binary people too because that's like-there's a lot of therapists who are great with MTF or FTM but not people who don't identify as one or the other. I think that that kind of experience is important because if they're coming at it with only having seen a few genderqueer patients they're not going to have the knowledge or the education or just the experience.

Like Nate, Clara feels that an individual working with the transgender community should do their best to become educated about transgender issues. Clara specifically cites a need to be familiar with multiple transgender identities. He explains that working with a person who is genderqueer or gender variant may require a different understanding than an individual who more closely follows a traditional transgender narrative.

Beatrice explains that his therapist did research after taking him on as a client. I don't know if she knew about it before we met but I think she definitely did a lot of reading up just because of seeing all of a sudden she has a lot of books on trans identity in her office now. I think she tried to learn about different things and she didn't really seem to project any identity specifically on me, she just kind of asked me a lot of questions to help me think about where I was.

Beatrice provides a positive review for his therapist due in part to his perception that his therapist educated herself about transgender issues. Without a working knowledge of alternatives to the traditional transgender narrative therapists may find it difficult to effectively work with gender variant individuals. It is suggested that those who take on 
gender variant clients work to educate themselves on ways to help their clients that vary from the Harry Benjamin Standards of Care.

Changes to the Standards of Care and Diagnostic \& Statistical Manual

The research question was written and data was collected for this study in 2010 and early 2011. Not long after that, the World Professional Association for Transgender Health (WPATH) published the Standards of Care 7 (SOC 7). The Diagnostic \& Statistical Manual (DSM V), published in 2013, then mirrored the SOC's changes in the treatment of transgender patients. Changes to the SOC relate to this research in two ways:

(1) The elimination and replacement of the label Gender Identity Disorder, (2) acknowledgement of the key seeker vs. explorer dichotomy and (3) relaxation of the gatekeeping role.

Elimination of Gender Identity Disorder \& Adoption of Gender Dysphoria

The SOC 7 has removed the label of Gender Identity Disorder and replaced it with Gender Dysphoria. In some ways, the new label of Gender Dysphoria and its requirements for diagnosis are a step in a positive direction. Most notably, the stringent instance on the gender binary by acknowledging and accepting those who identify as gender variant or genderqueer. Whereas previous versions of the SOC pathologized incongruence between presentation and sex assigned at birth, the SOC 7 explain that individuals, for example masculine women or feminine men, should not necessarily be thought of as pathological.

While the WPATH now recognizes gender variance, transgender people who wish to make changes to their bodies still stand to be labeled under the SOC 7. Within the first few pages the SOC states that "Some people experience gender dysphoria at such a 
level that the distress meets the criteria for a formal diagnosis that might be classified as a mental disorder" (168). It then goes on to say that "...transsexual, transgender and gender non-conforming individuals are not inherently disordered. Rather, the distress of gender dysphoria, when present, is the concern that might be diagnosable and for which various treatment options are available" (169). It seems that the change in label between Gender Identity Disorder and Gender Dysphoria is very subtle, and is thus still applicable to labeling theory. (See future research.)

\section{Acknowledgement of Key Seeker vs. Explorer}

Through examining identity shift this study identified that there were two types of gender variant individuals seeking therapy: Explorers and Key Seekers. (See Findings.) While explorers went to therapy to help sort out their feelings around gender and identity, Key Seekers went with the sole purpose of attaining a letter. The Standards of Care acknowledges this phenomenon, stating that "Some patients who present for care will have made significant self-directed progress toward gender role changes, transition, or other resolutions regarding their gender identity. Other patients will require more services" (167). While not directly acknowledging that some patients are there solely for access to hormones and/or surgeries, they have made it clear that not all transgender people need therapy sessions.

The SOC state that "A mental health screening and/or assessment as outlined above is needed for referral to hormonal and surgical treatments for gender dysphoria. In contrast, psychotherapy — although highly recommended - is not a requirement" (183). This means that while a therapist still holds the gatekeeper role, those who do not desire 
to do so can avoid traditional talk therapy. Instead, they are assessed in a single session, and then, if the therapist deems it appropriate, will receive their letter.

Relaxation of the Gatekeeping Role

Not only is psychotherapy no longer required, but the SOC now acknowledges the Informed Consent Model. The Informed Consent Model states that as long as an individual is aware of the potential effects of hormones or surgeries on their body, they can make the decision as to whether or not to go ahead with treatment without a referral letter. The SOC even goes as far as to say that informed consent model "protocols are consistent with guidelines presented in the WPATH Standards of Care, Verison 7." (188). The SOC explains that different interventions are needed based on the individual and community being served. However, it does explain that the difference between informed consent and SOC is that "SOC puts greater emphasis on the important role that mental health professionals can play in alleviating gender dysphoria and facilitating changes in gender role and psychological adjustment" (188).

It should be made clear that while the SOC 7 now acknowledges and supports the Informed Consent Model, it does not encourage it. The article that influences so many transgender and gender variant individuals' lives still makes clear that doctor's following the SOC 7 should require at least one letter from a mental health professional before providing aids to change physical sex characteristics.

Prior to the SOC 7 acknowledging the Informed Consent Model, as shown previously through the data and literature, the informed consent model was active in some transgender health centers. However, the Informed Consent Model was not widely available. It is not probable that the framing of the Informed Consent Model has been 
helped by the SOC 7. The SOC 7 still presents the model of mental health professional as gatekeeper as the best guidelines for the transgender medical system. However, Informed Consent existed prior to the weak acknowledgment the WPATH gave it, and will hopefully continue to grow in spite of its lack of real support.

\section{Suggestions for Future Research}

This study was designed to be exploratory, meaning that it in part intended to help develop a template for looking at therapy, identity, and gender variant individuals. It was also intended to reveal areas that should be further studied. Three key areas have been identified that would benefit from additional research are: Restructured labeling theory, larger sample size and interviews with mental health professionals. The DSM 7 label change from GID to Gender Dysphoria should also be studied. Restructured Labeling Theory

Working with this data in relation to labeling theory has revealed an aspect of labeling theory that is in need of future research. The first is interpersonal vs. official labels. It has been argued that labeling occurs from multiple sources. Participants were able to reject the interpersonal label or GID that came from the therapist through methods of avoidance, yet could not escape the official diagnosis. Official diagnosis was necessary due to the link between the mental health system and medical system. This brings into question what it means to avoid a label. If an individual rejects the interpersonal label yet is forced to accept the official diagnosis, does this mean that they have successfully avoided the label of GID and the affects it may have on them? A future comparison between interpersonal and official labeling may provide additional insight into labeling theory. 


\section{Interviews with Mental Health Professionals}

This study utilized client perspectives in order to analyze therapist's behaviors within the therapy setting. While talking with mental health professionals was not possible due to the time and resources of this study, it is something that I would like to include in future research. Talking directly to mental health professionals will provide a perspective of not only their actions, but also the motives behind those actions. Asking therapists direct questions will allow for a comparison of beliefs about gender and diagnosis between therapists and their transgender clients.

\section{Larger Sample Size}

This study looked at twelve transgender individuals who currently or formerly identify as gender variant. Due to its small sample size and sampling strategy, results are not generalizable to the gender variant community as a whole. In order to better speak for the gender variant community more voices need to be listened to. Inclusion of transgender individuals who do not identify as gender variant is also suggested, as gender variant individuals seem to be a highly educated subsect of the transgender population. The nature of this study meant that some groups were underrepresented, resulting in a high ability to avoid the GID label.

Three groups in particular should be sought in order to make research in this area more comprehensive. These groups include those assigned male at birth (MAAB), those with no college experience and those who accept the label of Gender Identity Disorder. This study included no individuals who were MAAB. Those who are MAAB may have a different experience with mental health providers than those female assigned at birth, and thus might have differing experiences in therapy. The sample was also heavily educated, 
with only one participant, Mack, having never been enrolled in college. Mack also was the only individual who accepted the label of GID. It was expected that more of the sample would accept the label of GID, but that turned out not to be the case.

Purposive sampling to increase the amount of MAAB and lesser educated individuals should be utilized. In the future I would like to conduct a large scale study that includes not only those who identify as gender variant, but all transgender, transsexual, or gender variant individuals who seek mental healthcare and/or desire to use the mental healthcare system as a means to acquire medical body modifications. Broadening the group being sampled to serve all of the transgender community while purposively sampling for assigned sex and level of education will allow for a more extensive amount of individuals to be reached.

Gender Identity Disorder vs Gender Dysphoria and Labeling Theory

The WPATH describes being gender variant as one of the many non-pathologized options for presenting as a human. However, the feelings of distress caused by not being perceived as the gender one desires to be perceived as, or feeling uncomfortable with one's sex characteristics, is still diagnosable. The change in label supported by the WPATH and APA allow for new research questions that address this change.

Do transgender individuals accept or reject the label of Gender Dysphoria? Are transgender individuals more likely to accept the less harsh term "dysphoria" over the stigmatized term "disorder?" This research found that many rejected the term Gender Identity Disorder not necessarily because they opposed the idea of being labeled, but because they opposed the connotation that being transgender is "disordered." The SOC 7 
have made a large effort not to stigmatize transgender and gender variant people, which may cause less friction between the groups.

If transgender individuals do accept the label of "Gender Dysphoria," the application of labeling theory to transgender individuals may be further explored. As a follow up to this study, it would be interesting to gather data as to when those who accepted the term of gender dysphoria experienced identity shifts. What changes to the Key Seekers behaviors are seen with the more relaxed process of receiving a letter?

\section{Conclusion}

This study set out to assess the possibility that gender therapy has a relationship to the formation of gender identity for gender variant individuals. Labeling theory was utilized as a framework to explore the potential of therapy having a causal relationship to gender identity formation. Twelve individuals who self identified as currently or formerly gender variant were interviewed in order to assess identity shifts during the therapy process. It was found that the majority of participants rejected the label of GID through three methods of avoidance: (1) Informed Consent, (2) Shopping for Therapists and (3) Creative Wording and Hoop Jumping. While it was expected that a portion of the sample would accept the label of GID, only one did. This made a comparison between those who accept and those who reject the label impossible. Furthermore, the one individual who accepted the GID label saw no change in identity while in therapy. There is no support for the idea that acceptance of the GID label leads to identity shift in this small sample.

However, the data show that identity shifts during therapy still occurred in nine participants. Through stepping away from labeling theory and exploring other potential causes for identity shift during therapy it was found that in all cases motivation for 
attending therapy corresponded with whether or not the individual had an identity shift in therapy. Those who entered therapy solely to gain access to hormones or surgery (key seekers) saw no shift in identity, while those who desired counseling about their gender identity (explorers) all saw a shift in their identity.

While the potential of gender identity shift as a result of labeling was not documented in this study, this may be due to the highly educated and privileged nature of the sample. The study chose to look at gender variant individuals instead of the broader transgender population due to the specific nature of the gender variant identity. It was predicted that as gender variant individuals identified as outside of traditional gender categories, a shift in identity caused by the mental illness label would be readily identifiable. What was instead found is that gender variant individuals with enough capital were able to sidestep being labeled altogether. The ability to sidestep the label due to power and resources was in itself a contribution to labeling theory, as it reinforces the idea that the ability to label comes from a position of power.

This study also listened to the desires of gender variant individuals for reform in mental healthcare. As demonstrated through the multiple methods of avoidance, many participants exerted energy in order to avoid being labeled with GID. Some participants also felt that they would benefit from a therapist who was educated in perspectives about gender that came from the gender variant community. Removing the gatekeeper role of the mental health profession, as well as providing resources for therapists to understand multiple perspectives on gender and identity, would allow for a therapy environment that is better suited to the client's needs. 


\section{References}

American Psychiatric Association DSM-5 Development. 2010. "Gender Identity Disorder in Adolescents and Adults."Arlington, VA: American Psychiatric Association. Retrieved March 18, 2010

(http://www.dsm5.org/ProposedRevisions/Pages/proposedrevision.aspx?rid=482)

Billings, Dwight B. and Thomas Urban. 1982. "The Socio-Medical Construction of Trasexualism: An Interpretation and Critique." University of California Press 29(3):266-288

Bower, Herbert. 2001. "The gender identity disorder in the DSM-IV classification: a critical evaluation." Melbourne, Victoria: Australian and New Zealand Journal of Psychiatry. 35:1-8.

Brown, Mildred L. and Chloe A. Rounsley. 2003. True Selves: Understanding Transexualism. San Francisco, CA: Jossey-Bass Books.

Clements-Nolle, Kristen, Rami Marx and Mitchell Katz. 2006. "Attempted Suicide Among Transgender Persons: The Influence of Gender-based Discrimination and Victimization.” Journal of Homosexuality 51(3): 53-69.

Denny, Dallas. 2004. "Changing Models of Transexualism.” Journal of Gay and Lesbian Psychotherapy 8(1/2):25-40.

Dewey, Jodie M. 2008. "Knowledge Legitimacy: How Trans-Patient Behavior Supports and Challenges Current Medical Knowledge." Qualitative Health Research 18(10): 1345-1355.

Gainor, Kathy A. 2000. "Including Transgender Issues in Lesbian, Gay and Bisexual Psychology." Pp. 131-160 in Education, Research, and Practice in Lesbian, Gay, Bisexual, and Transgendered Psychology, edited by Beverly Greene and Gladys L. Croom.Thousand Oaks CA: Sage Publications.

Genge, Patricia and Richard Tewksbury. 1999. Knowledge and Power, Body and Self: An

Analysis of Knowledge Systems and the Transgendered Self. The Sociological Quarterly 40(1):59-83.

Gove, Walter R. "Societal Reaction as an Explanation of Mental Illness: An Evaluation." American Sociological Review 35(5):873-884 
Grant, J. M., Mottet, L. A., Tanis, J., Herman, J. L., Harrison, J., \& Keisling, M. (2010). National Transgender Discrimination Survey Report on health and health care. National Center for Transgender Equality and National Gay and Lesbian Task Force. Washington, DC, 1-23.

Hale, Jacob C. 2007. "Ethical Problems with the Mental Health Evaluation Standards of Care Medicine

For Adult Gender Variant Prospective Patients.” Perspectives of Biology and 50(4): 491-505

Horwitz, Allan V. 2003. Creating Mental Illness. Chicago: University of Chicago Press

Lev, Arlene I. 2009. "The Ten Tasks of the Mental Health Provider: Recommendations for

Revisions of The World Professional Association for Transgender Health's Standards of Care. International Journal of Transgenderism 11:74-99

Meyer-Bahlburg, Heino F. L. 2009. "From Mental Disorder to Iatrogenic Hypogonadism: Dilemmas in Conceptualizing Gender Identity Variants as Psychiatric conditions." New York, NY: Archives of Sexual Behavior.

Nestle, Joan, Wilchins, Riki and Clare Howell. 2002. GenderQueer: Voices from Beyond the Sexual Binary. Los Angeles, CA: Alyson Publications.

Prior, Pauline M. 1999. BOOK NAME CURRENTLY UNKNOWN. New York, NY: NYU Press.

Ragin, Charles C. 1994. Constructing Social Research. Thousand Oaks, CA: Pine Forge Press.

Roen, Katrina. 2002. "Either/Or" and "Both/Neither": Discursive Tensions in Transgender Politics. Chicago Journals 27(2):501-522.

Scheff, Thomas J. 1963. The Role of the Mentally Ill and the Dynamics of Mental Disorder: A Research Framework. Sociometry 26(4):463-453.

Spradley, James P. 1979. The Ethnographic Interview. New York, NY: Holt, Rinhrt and Winston.

Thoits, Peggy A. 1985. Self-Labeling Process in Mental Illness: The Role of Emotional Deviance. The American Journal of Sociology 91(2):221-249. 
Vanderburgh, Reid. 2007. Transition and Beyond: Observations on Gender Identity. Portland, OR: Q Press.

Weiss, Robert S. 1994. Learning from Strangers. New York, NY: The Free Press.

Whittle, Stephan. 1996. "Gender Fucking or Fucking Gender?: Current Cultural Contributions to Theories of Gender Blending." Pp. 196-214 in Blending Genders: Social Aspects of Cross-dressing and Sex-changing, edited by Richard Ekins and Dave King. New York, NY: Routledge. 
APPENDIX A1- Interview Invitational Video

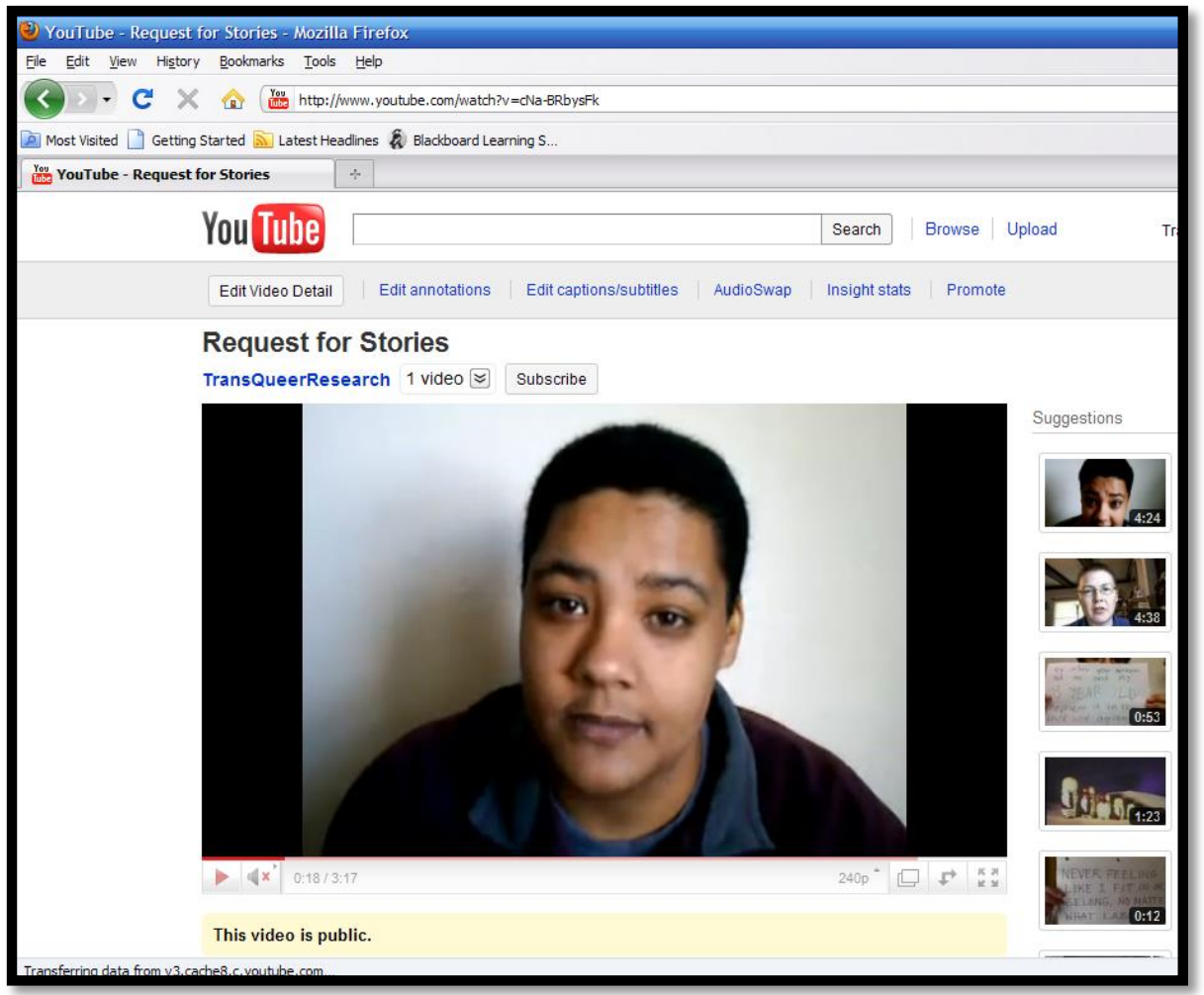


APPENDIX A2-Interview Invitational Letter

November 29, 2010

Hello,

My name is Dylan Waller, and I am a graduate student in the sociology department of Portland State University. I am conducting a research study and am seeking transgender individuals to participate.

Specifically, I am studying the experiences of transgender people during therapy. In order to participate in this study, you must meet three criteria. First, you must have selfidentified as somewhere outside of the gender binary at some point during your therapy. Identities that may fit this category may include, but are not limited to, genderqueer, gender neutral, genderless, butch, transmasculine and much more. Second, you must have been involved in therapy sessions in which you specifically discussed your gender identity. Last, during some point during the duration of your therapy sessions you must have potentially desired receiving a letter from your therapist that would allow you to receive surgery and/or hormones. It is not necessary for you to have asked for or received the letter, but rather that you had the desire to keep that option open to yourself.

If you decide to participate in this study you will be asked to talk with me over the telephone about your gender identity and your experiences in therapy. The interview will take place during a time we both agree upon, and will last no more than two hours. You have the right not to answer any of the questions I ask you. You also have the right to discontinue the study at any time. The interview will be audio recorded so that I can accurately recall our conversation at a later time. Interviews are confidential, and I will be the only person with access to the voice recordings. While results of this study may be published or presented at professional conferences, your identity will not be revealed.

Although you may not benefit directly from participating in this study, I feel that that this study will benefit the community as a whole. My intent in conducting this study is to give voice to a segment of the trans community that is often overlooked. Through having our voices heard I believe that we can make a positive difference in the way that we are cared for by therapists.

I am happy to answer any questions you have about this study. Similarly, if you are interested in potentially taking place in this study, please contact me at waller.dylan@gmail.com.

Best wishes,

Dylan Waller 


\section{APPENDIX B - INTERVIEW GUIDE}

\section{Prior to Interview, perform the following tasks:}

$€$ Confirm that I am talking to participant

$€$ Reintroduce self, say hello

$€$ (If not yet in possession) Confirm that participant has read agrees to consent form

$€$ Explain "conversational" structure of interview

$€$ Explain participant's right to stop interview or skip questions

$€$ Ask if participant has any questions before beginning

\section{A- Identity/Gender Presentation}

First, I'd like you to tell me the story of your gender identity over time. I want to know if your identity has changed over time. In this story, start before you began to question your identity and end at your current identity. Take as much or as little time as you'd like.

\section{B- Societal Perceptions}

On a day to day level, how would you say that those around you respond to your gender presentation?

Probe: How do you feel about these responses?

Tell me about a time when you've felt someone outside your immediate circle reacted positively to your presentation.

Probe: How did you feel when this event happened to you?

Tell me about a time when you've felt someone outside your immediate circle reacted negatively to your presentation.

Probe: How did you feel when this event happened to you?

\section{C- Belief in/ Knowledge of Medical Model}

Tell me what you know about the Harry Benjamin Standards of Care.

When did you learn about them?

\section{BEFORE THERAPY/DURING THERAPY/AFTER THERAPY}

What is your opinion about the Harry Benjamin Standards of Care?

Tell me what you know about the WPATH Standards of Care. 
When did you learn about them?

BEFORE THERAPY/DURING THERAPY/AFTER THERAPY

What is your opinion about the WPATH Standards of Care?

Tell me what you know about the term Gender Identity Disorder?

When did you learn about this?

BEFORE THERAPY/DURING THERAPY/AFTER THERAPY

What is your opinion of Gender Identity Disorder?

IF POSITIVE OPINION- Do you believe you have Gender Identity Disorder?

IF YES- When did you first know that you had GID?

\section{D- Social Support}

Are you involved with any trans activities or groups?

IF YES- What are they?

IF YES- How long have you been involved?

Do you feel you have individuals in your life who are supportive of your gender?

What relation do they hold to you?

In which ways do they express their support?

Tell me about where you draw support or guidance about your gender from?

Do you feel that there are or were individuals in your life who are not supportive of your gender?

What relation do they hold to you?

In which ways were they not supportive?

\section{F- Therapy}

I'd like you to tell me another story. Tell me the story of your experience in therapy as it relates to gender.

Checklist

$€$ Choosing a therapist

$€$ Advice prior to therapy 


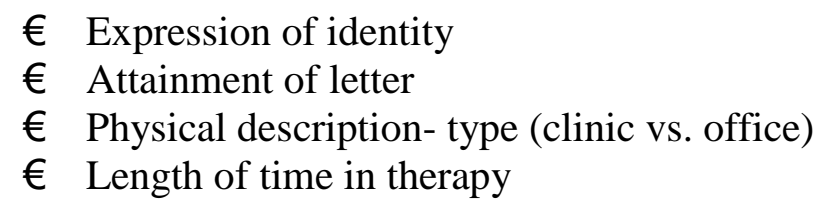

At any point during therapy did you feel the desire to express being [gender variant identity]?

Did you choose to express these feelings?

IF UNCLEAR- Why did you [choose/choose not to] express these feelings?

IF YES- How did you express these feelings? identity]?

IF YES- How did your therapist react to the expression of your [gender variant

How did you choose which therapist you would seek for gender counseling?

What criteria did you use in choosing a therapist?

Did you know anything about your therapist prior to your initial visit? What?

Did you receive any advice prior to attending your therapy sessions?

IF YES- Who did you receive this advice from?

IF YES- What advice did you receive?

What did you feel your therapists beliefs about gender were?

Did you feel that your therapist understood the concept of identifying with more than one gender?

Did you feel that your therapist felt that identifying with more than one gender was an acceptable thing to do?

What did your therapist do to make you feel this way?

Did you ask for a letter from your therapist?

IF YES- Did you receive your letter?

IF YES- Did you feel that you needed to be perceived by your therapist in a certain way in order to gain your letter?

IF NO PROBE IF UNCLEAR - Why didn't you ask for a letter from your therapist?

IF NO (Not required for surgery/hormones)- If you had asked for a letter, do you feel your therapist would have provided it to you?

What makes you feel this way?

IF NO (Did not desire hormones/surgery)- If you had asked for a letter, do you feel your therapist would have provided it to you?

What makes you feel this way? 
IF NO (Due to therapist behavior)- In which ways did your therapist behave that made you feel like you couldn't ask for a letter?

What advice would you give someone entering therapy in order to get a letter?

How would you rate your experience in therapy?

VERY POSITIVE - VERY NEGATIVE (Likert)

Would you recommend the therapist you used to others?

How could your therapist have improved your sessions?

I don't have any more questions for you about therapy. Is there anything that I didn't ask you that you think I should know?

\section{E- Demographics}

Pseudonym:

Ethnicity:

Age :

Occupation:

Level of Education:

How would you describe where you are originally from?

CITY/SUBURB/SMALL TOWN/OTHER (ASK)

State of Origin:

How would you describe location you received therapy?

CITY/SUBURB/SMALL TOWN/OTHER (ASK)

State of therapy:

\section{In closing interview:}

$€$ Thank participant

$€$ Ask if participant has any questions 
$€$ Let participant know that they can contact me in the future if they desire 